ARGONNE NATIONAL LABORATORY

9700 South Cass Avenue, Argonne, Illinois 60439

ANL $-01 / 28$

\title{
DESIGN AND DEMONSTRATION OF MULTIPORT CYLINDER DRYER: FINAL REPORT ON THE MULTIPORT DRYER PROJECT IN PHASE 1
}

by

\author{
S. U. S. Choi, W. Yu, M. W. Wambsganss, T.-H. Chien, and J. Harkness ${ }^{\dagger}$ \\ Energy Technology Division \\ †Energy Systems Division \\ Argonne National Laboratory \\ Argonne, IL 60439 \\ D. M. France \\ University of Illinois at Chicago \\ Department of Mechanical Engineering, M/C 251 \\ $842 \mathrm{~W}$. Taylor Street \\ Chicago, IL 60607-7022 \\ D. K. Barde, W. D. Vallance, and C. W. Stewart \\ Eastern Pulp and Paper Corporation \\ 100 University Dr. \\ Amherst, MA 01002 \\ J. L. Timm \\ The Johnson Corporation \\ 805 Wood Street \\ Three Rivers, MI 49093
}

October 2001

Work supported by

U.S. DEPARTMENT OF ENERGY

Office of Energy Efficiency and Renewable Energy, Office of Industrial Technologies 


\section{Contents}

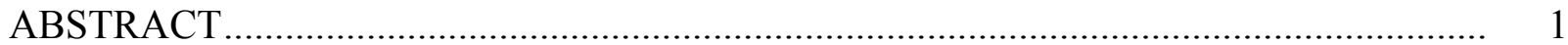

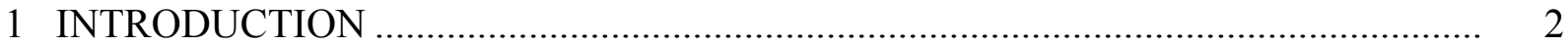

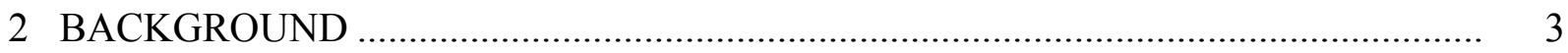

3 CONCEPT AND CHARACTERISTICS OF MULTIPORT CYLINDER DRYER........ 6

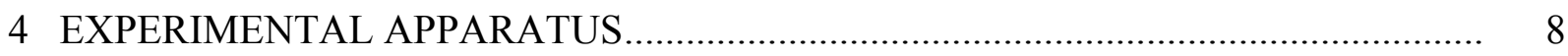

5 TEST APPARATUS OPERATING PROCEDURES ………....................................... 13

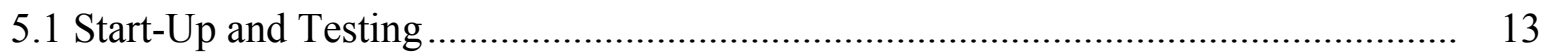

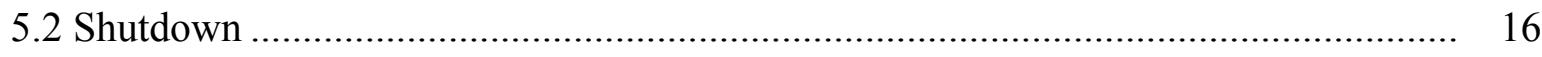

6 DATA ACQUISITION AND REDUCTION ……….............................................. 16

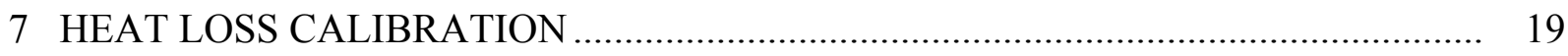

8 EXPERIMENTAL RESULTS AND DISCUSSION ……............................................ 20

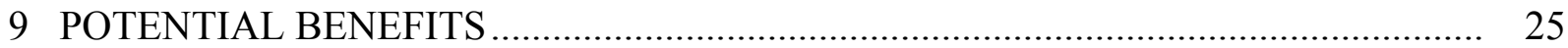

9.1 Comparison with Conventional Cylinder Dryers .................................................... 25

9.2 Potential Benefits and Impacts .......................................................................... 25

10 FUTURE WORK AND EXPECTED RESULTS ………………............................... 28

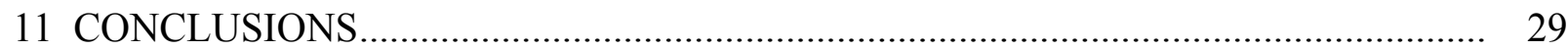

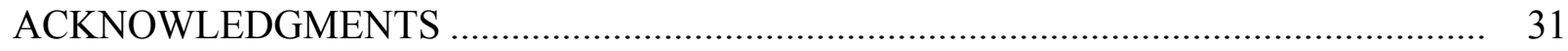

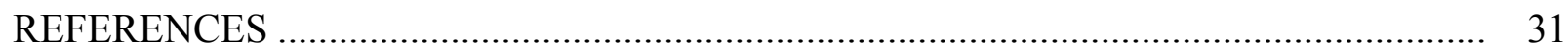

APPENDIX: Energy Savings and Waste Reduction Analysis for the Multiport Dryer

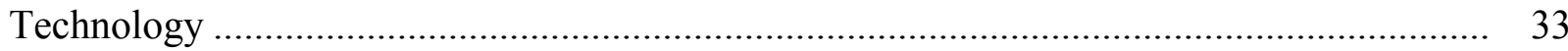




\section{Figures}

1 Resistances to heat transfer on cylinder dryer............................................................

2 Percentage contribution rates of heat transfer resistances............................................ 5

3 Schematic representation of multiport cylinder dryer concept................................... 7

4 Digital picture of multiport dryer heat transfer test apparatus .................................... 9

5 Schematic representation of multiport cylinder dryer heat transfer test apparatus ...... 10

6 Detailed schematic representation of test section...................................................... 11

7 Heat loss, based on single-phase heat transfer tests, as a function of temperature difference between wall and ambient ................................................................... 20

8 Average condensing heat transfer coefficients as function of mass flux ……............ 22

9 Average condensing heat transfer coefficients as function of pressure ..................... 23

10 Local condensing heat transfer coefficients as function of quality ............................ 23

11 Temperature distribution .................................................................................. 24

12 Two-phase pressure gradient as function of mass flux ............................................ 24

13 Average condensing heat transfer coefficients of multiport and conventional

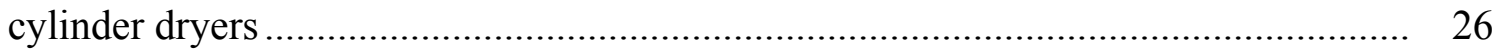

14 Increased drying rate as a result of multiport technology ......................................... 27

\section{Tables}

1 Value/range of experimental parameters.............................................................. 21

A1 Energy savings and decreased $\mathrm{CO}_{2}$ emissions by Multiport Dryer technology ......... 38 


\title{
DESIGN AND DEMONSTRATION OF MULTIPORT CYLINDER DRYER: FINAL REPORT ON THE MULTIPORT DRYER PROJECT IN PHASE 1
}

\author{
by \\ S. U. S. Choi, W. Yu, M. W. Wambsganss, T.-H. Chien, J. Harkness, \\ D. M. France, D. K. Barde, W. D. Vallance, C. W. Stewart, and J. L. Timm
}

\section{ABSTRACT}

The rate of paper drying is one of the critical technical barriers in the production of pulp and paper. The concept of multiport cylinder dryers developed by Argonne National Laboratory is an innovative idea that could create breakthroughs in the drying of pulp and paper. In a multiport dryer, steam flows through "ports," or longitudinally oriented passages, close to the dryer surface. This design, which minimizes the "rim of condensate" and offers a larger surface area for drying, thereby increasing the drying rates, also uses forced heat convection, which is more effective as a heat-transfer mechanism than heat conduction in the conventional dryer design. The feasibility of this novel concept was demonstrated in a proof-of-concept test. Experiments were performed in a specially designed apparatus to investigate the condensing heat transfer characteristics of a single channel that is representative of a multiport dryer (MD) under typical operating conditions. The experimental results showed that multiport-cylinder-dryer technology provides very high heat-transfer coefficients of $15,000 \mathrm{~W} / \mathrm{m}^{2} \cdot \mathrm{K}\left(2,600 \mathrm{Btu} / \mathrm{h} \cdot \mathrm{ft}^{2} \cdot{ }^{\circ} \mathrm{F}\right)$ and a highly uniform distribution of cylinder-wall temperature. Laboratory-scale tests and assessments suggest that a multiport cylinder dryer can potentially increase paper drying or production rates by as much as $20 \%$ when compared with spoiler bar technology, and by as much as $90 \%$ when compared with existing technology without spoiler bars. The increased dryer efficiency translates into either a reduction in the number of dryers at the same level of production or an increase in the rate of production with the same number of dryers. Multiport dryer technology is important to the pulp and paper industry because it will have a major impact on improved productivity and capital effectiveness. This innovative approach can be used to retrofit existing dryers or to reshape next-generation new dryers.

Phase 1 of the MD Project has successfully demonstrated the feasibility of the concept. However, the practical effects of a full-scale model MD are still unknown, and so MD performance tests in a full-scale, rotating test dryer will be conducted in Phase 2 of the MD Project. 


\section{INTRODUCTION}

The pulp and paper industry is among the most capital-intensive manufacturing industries in the United States. The large dryers that remove residual water from the paper are the most costly components associated with papermaking. A serious problem that impedes higher productivity and capital effectiveness is that the existing paper machines are dryer-limited. Currently improved productivity can be achieved only at the expense of high capital cost because new dryers are expensive and innovative retrofit technologies are not available yet. With increasing global competition, the industry urgently needs a dramatic breakthrough in drying technology to obtain an edge over foreign competitors. A higher drying or evaporation rate will reduce the number of dryers needed and/or raise dryer operating velocity, which means higher productivity and stronger competitiveness. So there is a strong interest in reducing capital and operating costs through enhanced heat transfer performance in the dryers.

Since 1988, Argonne National Laboratory (ANL) has conducted programs to develop highperformance, compact heat exchangers for application in the process industries, automobile air conditioner systems, and ANL's Advanced Photon Source mirror-cooling devices [1-3]. The thermal sciences program has developed the technology base that facilitates the application of compact evaporators and condensers in the process industries and the high-performance condensers program has studied condensation in small passages of multiport condenser tubes in automobile air conditioner systems. Based on the concept of compact, small-channel heat exchangers with high surface area density ratios and realizing that small-channel heat exchanger technology can offer a radically new approach to increasing paper-drying rates, ANL has developed a multiport dryer (MD) design concept that allows the use of multiport channels to force the steam into contact with the cylinder wall [4]. This distinctly new design allows the cylinder dryers to operate at maximum drying rates by minimizing the thermal resistance of the condensate and maximizing the heat transfer surface area.

The automobile industry has already adopted the general approach of a high-performance, compact, multiport condenser to improve the performance of the condensers in its commercial air-conditioning systems. However, ANL's idea to apply the high-performance, small-channel, heat exchanger technology specifically to drying of pulp and paper is the first of its kind. Although high-performance multiport heat exchanger technology has been proved in other fields, experimentation is required to demonstrate feasibility for paper drying. Therefore, the objective of this project is to demonstrate the feasibility of the MD concept and potential benefits of MDs over conventional cylinder dryers. To be commercially viable, the MD design should be capable of being retrofitted in existing installations. Therefore, the project focused on the development and demonstration of a multiport dryer technology that will provide users of steam-heated cylinder dryers with increased drying rates in existing cylinder dryer installations at competitive retrofit costs. 
To demonstrate the feasibility of MDs for pulp and paper drying, a laboratory-scale MD heat transfer test apparatus was designed and fabricated at ANL, in collaboration with the University of Illinois at Chicago, Eastern Pulp and Paper, and The Johnson Corporation. Engineers at Eastern have provided input to the basic MD design to ensure that the design is commercially viable, and to the test program, to ensure that the test conditions simulate industrial operating conditions. Engineers at Johnson have provided input on condensate removal. Experiments were performed in a specially designed test apparatus to investigate the condensing heat transfer characteristics of a single channel, representative of a multiport cylinder dryer, under typical operating conditions, and to demonstrate the advantages of a multiport cylinder dryer over conventional cylinder dryers.

In 1997, ANL successfully developed a top-ranked MD project in the energy performance category of the American Forest and Paper Association's Vision 2020 Initiative. The project was funded for two years (FY 1998 - 1999) by the DOE Office of Industrial Technologies and with in-kind cost share by the two industrial partners, Eastern Paper and The Johnson Corporation. Phase 1 of the MD Project has been conducted by an R\&D team from ANL, the University of Illinois at Chicago, The Johnson Corporation, and Eastern Pulp and Paper. This final report shows that Phase 1 of the MD Project successfully demonstrated the feasibility of the concept of an MD. However, the practical effects of a full-scale model MD are still unknown; thus, MD performance tests in a full-scale, rotating test dryer will be conducted in Phase 2 of the MD project. After Phase 2, the MD technology will be ready for commercial development by the industry.

\section{BACKGROUND}

In most papermaking machines, the wet web (containing $55-60 \%$ moisture) is passed over a series of rotating steam-heated drying cylinders. The water is evaporated from the paper and carried away by ventilation systems. The heat energy for drying the paper comes from steam inside the dryer cylinders. Heat is transferred from the steam inside the dryers to the wet sheet outside the dryers, providing the energy required for evaporation. As the heat is transferred from the steam, most of the steam condenses inside the dryers. Heat transferred from the steam to the wet sheet must overcome a series of thermal resistances. As shown in Fig. 1, these resistances include [5]

- Steam convection heat transfer resistance.

- Condensate layer.

- Scale inside the dryer.

- Dryer shell. 

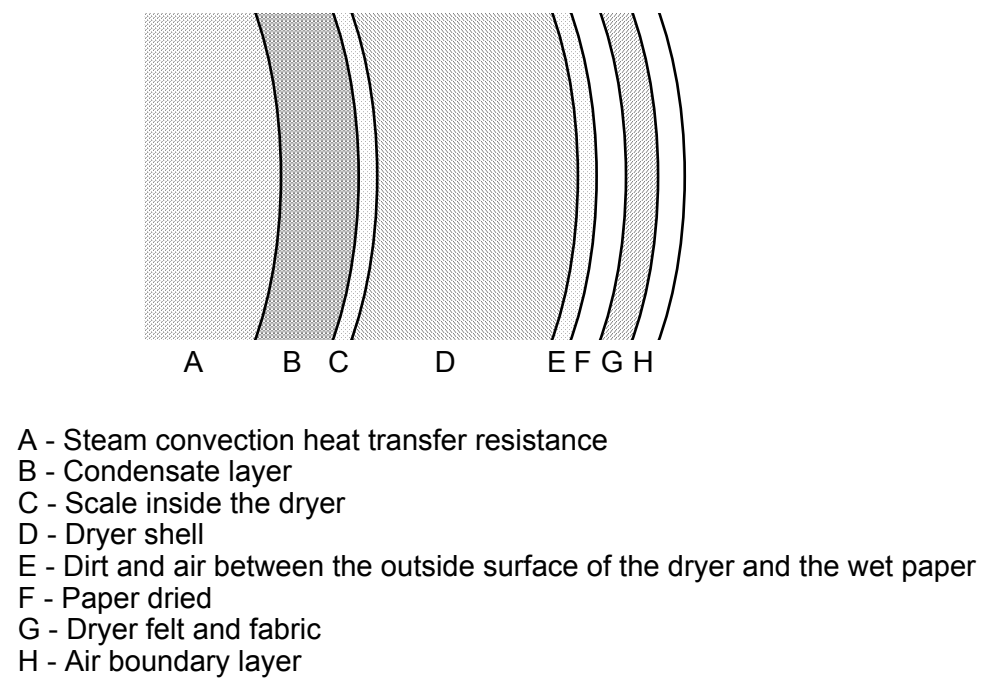

Fig. 1. Resistances to heat transfer on cylinder dryer

- Sheet-to-dryer contact, including

- Dirt and air between the outside surface of the dryer and the wet paper.

- Paper.

- Dryer felt or fabric.

- Air boundary layer.

Of these, the primary contributors to overall thermal resistance are the condensate layer, dryer shell, and sheet-to-dryer contact [6].

- Condensate Layer. As steam and liquid water flow through a series of conventional paper dryers, some condensate always remains in the steam drums as a condensate layer on the inner wall of the shell. Heat transferred from the steam to the wet sheet must pass through this film of condensate. The condensate is thus the first barrier or resistance to heat transfer. The thickness of the condensate layer is greatly affected by dryer speed; as the rotational speed of the cylinder increases, the contribution of the condensate layer to overall resistance also increases.

- Dryer Shell. The second primary barrier to heat transfer is the dryer shell, where resistance is affected by both shell thickness and shell thermal conductivity. Thickwalled shells with low thermal conductivity produce greater resistance to heat transfer than thin-walled shells with high thermal conductivity. 
- Sheet-to-Dryer Contact. The less-than-perfect contact between the outside surface of the dryer and the wet paper is the third primary resistance to heat transfer. Scale on the outside of the dryer, the thin film of air that separates the dryer from the paper, and the outer-surface conditions of the paper are the primary contributors to sheet-to-dryer contact resistance.

The magnitude of the contribution of each of these three resistances to the overall thermal resistance greatly depends on cylinder speed. Figure 2 shows a typical example of the percentage contribution rates of these three resistances to the overall resistance as a function of cylinder speed [7]. It can be seen that the condensate layer is the main obstacle to increasing cylinder speeds and thus productivity.

Many studies, focused on reducing the thickness of the condensate layer and its thermal resistance, have been performed for cylinder dryers. Some significant developments are noted below.

Siphons, as a condensate-removal device, are widely installed in newly designed cylinder dryers. Experimental studies show that the siphon clearance has an effect on dryer performance and that correctly designed condensate entrances will improve the drying rate and drying uniformity [8-12].

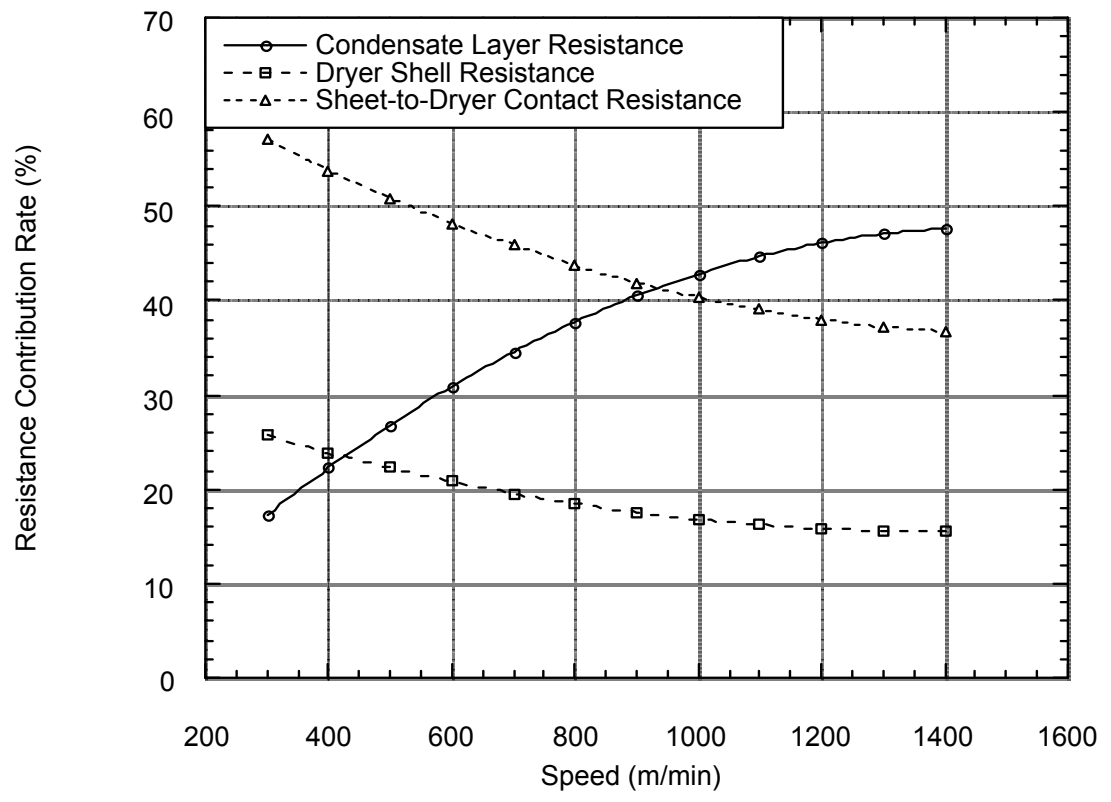

Fig. 2. Percentage contribution rates of heat transfer resistances 
In some cases, spoiler bars have been attached to the inside surface of the dryer shell, with the spacing between the bars selected to produce resonant waves in the condensate layer [6, 1314]. The increased turbulence not only increases the rate of heat transfer through the condensate layer, but also improves the uniformity of the moisture profile. The gains achieved by the use of spoiler bars depend on the existing equipment and operation. At low speeds, very little gain is expected because natural turbulence already produces high heat transfer rates. But at higher speeds, the drying rate may be increased $20-40 \%$ with the spoiler bars. In general, dryers with low contact resistance, well-ventilated pockets, and high steam pressures realize the highest percentage gain.

The basic concept of the cylinder dryer has remained unchanged since the advent of the conventional cylinder dryer. In contrast, ANL's high-performance, small-channel, heat exchanger technology for paper drying, i.e., multiport cylinder dryer technology, offers a radically new approach to increasing paper drying rates.

\section{CONCEPT AND CHARACTERISTICS OF MULTIPORT DRYER}

On high-speed machines, a layer of condensate that interferes with heat transfer during the drying operation forms inside the dryer cylinder. Therefore, the main objective of the MD design is to decrease the heat transfer resistance on the steam side, and thus improve the overall heat transfer coefficient. To increase the paper drying rate, i.e., productivity, we must improve the condensing heat transfer coefficients.

The key feature of the new dryer design derives from the observation that the thick layer of condensate formed around the inner surface of a conventional dryer represents a major resistance to heat flow that severely limits drying capacity. The basic concept of a multiport cylinder dryer is to flow the steam through many small "ports," or longitudinally oriented flow passages, close to the dryer surface during the drying process, as shown in Fig. 3.

In striking contrast to conventional cylinder dryers, the "rim of condensate" is minimized in the multiport cylinder dryer, and the dominant heat transfer mechanism is forced convection, which is markedly more effective than conduction, the dominant heat transfer mode in conventional dryers. Furthermore, the use of multiports in a cylinder dryer significantly increases the surface area, with the result that drying rates are significantly higher. All of these factors can contribute to extremely high coefficients of condensing heat transfer. 


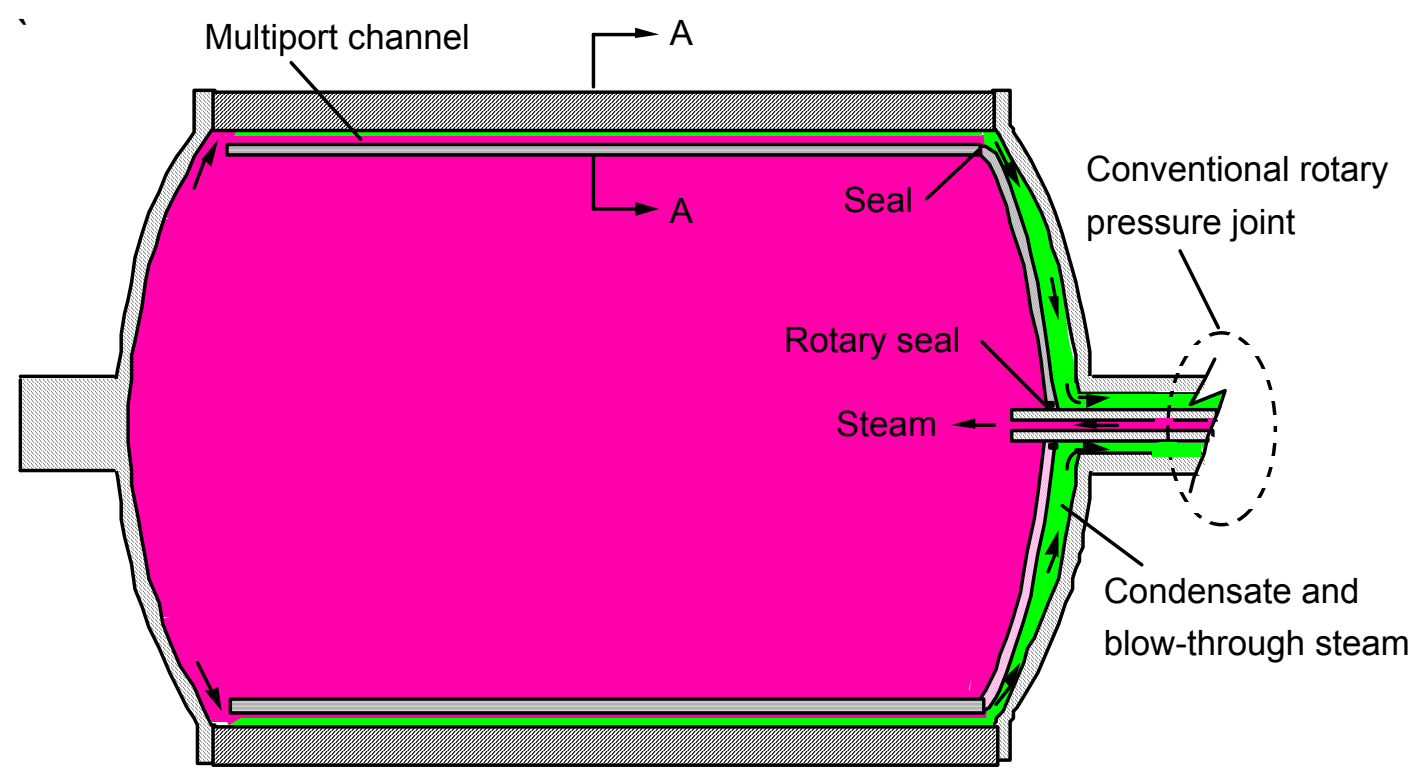

Multiport channel (typ.) Corrugations

Section A-A

Fig. 3. Schematic representation of multiport cylinder dryer concept

The characteristics and advantages of this innovative cylinder dryer are described below.

The condensate rim problem, when compared with that in conventional dryers, is minimized in the multiport configuration. The thickness of the condensate rim between the steam and the cylinder shell is limited in the MD by the small channel size. Because the geometry is self-limiting, there is a possibility of eliminating the need for a siphon extending to the cylinder wall.

The heat transfer mechanism is dominated by forced convection rather than conduction through a thick condensate rim; higher heat transfer efficiency is achieved on the steam side.

The steam flows through passages close to the cylinder dryer surface. The side walls of the steam passages produce a positive fin effect on heat transfer. Together, these conditions produce a multiport cylinder dryer with a large effective heat transfer surface area.

All of the above factors contribute to the significant improvement of the condensing heat transfer coefficient and the overall heat transfer coefficient for the multiport cylinder dryer over the conventional cylinder dryer. 
The structure of the multiport cylinder dryer also provides for the possibility of further enhancing heat transfer. Surface enhancement on flow inserts, such as twisted tapes, could be used to increase the heat transfer rate beyond the smooth open flow channel considered here.

Because of its high condensing heat transfer coefficient, the multiport cylinder dryer can operate at higher speeds, which tend to minimize scale/fouling buildup and further reduce overall thermal resistance.

For new applications, the multiport channels can be designed to serve as "pressure vessels," by allowing much thinner cylinder walls that can be less expensive to fabricate, e.g., by rolling rather than casting. The thinner cylinder wall also decreases the thermal resistance of the shell and adds to the already-improved overall heat transfer coefficient. Thickness may be reduced from the existing $50-75 \mathrm{~mm}(2-3 \mathrm{in}$.) to $\approx 5-10 \mathrm{~mm}(0.2-0.4 \mathrm{in}$.) with the addition of structural support.

The multiport cylinder dryer technology can be used to cost-effectively retrofit existing, conventional steam-heated cylinder dryers to obtain increased drying rates.

\section{EXPERIMENTAL APPARATUS}

The apparatus was designed and fabricated to study condensing heat transfer of steam at pressures up to $1035 \mathrm{kPa}(150 \mathrm{psi})$ and temperatures up to $180^{\circ} \mathrm{C}\left(356^{\circ} \mathrm{F}\right)$ in a small rectangular channel. Figure 4 shows a digital picture of the MD heat transfer test apparatus. The channel cross-sectional area, pressure, and temperature are typical for a multiport cylinder dryer. The facility includes four flow loops, as described below, and shown schematically in Fig. 5. The test section, which is itself a heat exchanger, is between the water/steam loop and the water/coolant loop.

The MultiTherm loop, which generates steam, consists of two heat exchangers (designated Evaporator/Superheater and Heater in Fig. 5) and a high-temperature heat transfer liquid, MultiTherm (MultiTherm Corp.). The liquid is heated without boiling to $230^{\circ} \mathrm{C}\left(446^{\circ} \mathrm{F}\right)$ by electrical resistance in the heater. The hot liquid is used in the evaporator/superheater to boil water that will subsequently be condensed in the test section. The heater was designed with seven 19.05-mm-diameter (0.75-in.-diameter) cartridge heaters with a power output of 5,000 W $(17,061 \mathrm{Btu} / \mathrm{hr})$ to two heaters, $2500 \mathrm{~W}(8,530 \mathrm{Btu} / \mathrm{hr})$ to one heater, and $625 \mathrm{~W}(2,133 \mathrm{Btu} / \mathrm{hr})$ 


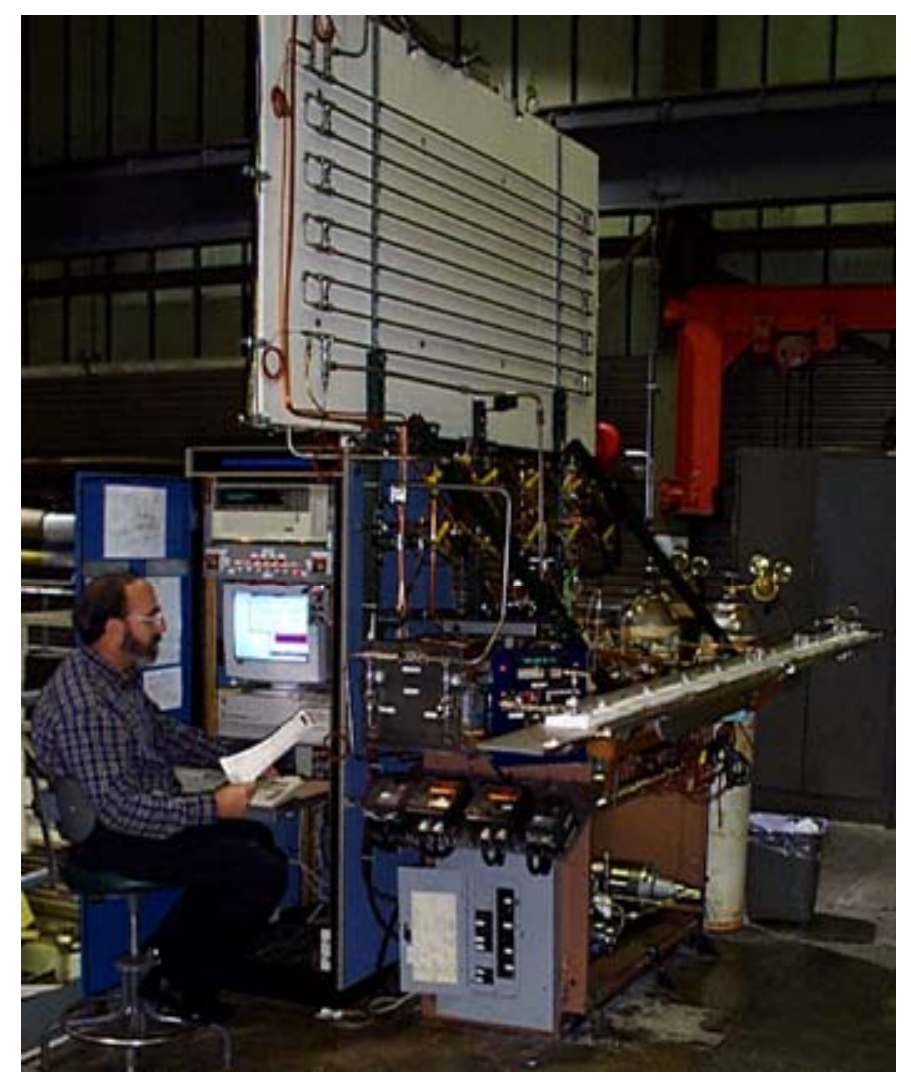

Fig. 4. Digital picture of multiport dryer heat transfer test apparatus

for the other four heaters. The electrical cartridge heaters can be turned on and off individually, and with a rheostat on one $625-\mathrm{W}(2,133-\mathrm{Btu} / \mathrm{hr})$ heater, any power up to $15 \mathrm{~kW}(51,182 \mathrm{Btu} / \mathrm{hr})$ can be attained.

As shown in Fig. 5, the MultiTherm liquid is pumped by Pump P-3 from the evaporator/superheater to the heater. A piston-type flowmeter (MAX Machinery) is used to measure the volumetric flow. A temperature sensor just upstream from the flowmeter provides a measure of the liquid temperature $T_{F M 3}$, which, in turn, allows calculation of the density of the MultiTherm liquid at the flowmeter and the mass flow rate. The liquid is electrically heated to $230^{\circ} \mathrm{C}\left(446^{\circ} \mathrm{F}\right)$ in the heater and generates steam in the evaporator/superheater. The heat that is transferred to the steam is controlled by the liquid mass flux, which is controlled to a desired value by an $\mathrm{AC}$ adjustable-frequency drive, and the heat provided to the liquid in the heater.

In the water/steam loop, as shown in Fig. 5, Pump P-1 is used to pump water from the after-condenser into the evaporator/superheater. A rotameter (Omega) is used to measure the volumetric flow, while a temperature sensor just upstream from the flowmeter provides a measure of the water temperature $T_{F M 1}$, which, in turn, allows calculation of the water density at the flowmeter and the mass flow rate. The volumetric flow can be controlled to a desired value with an AC adjustable-frequency drive. 

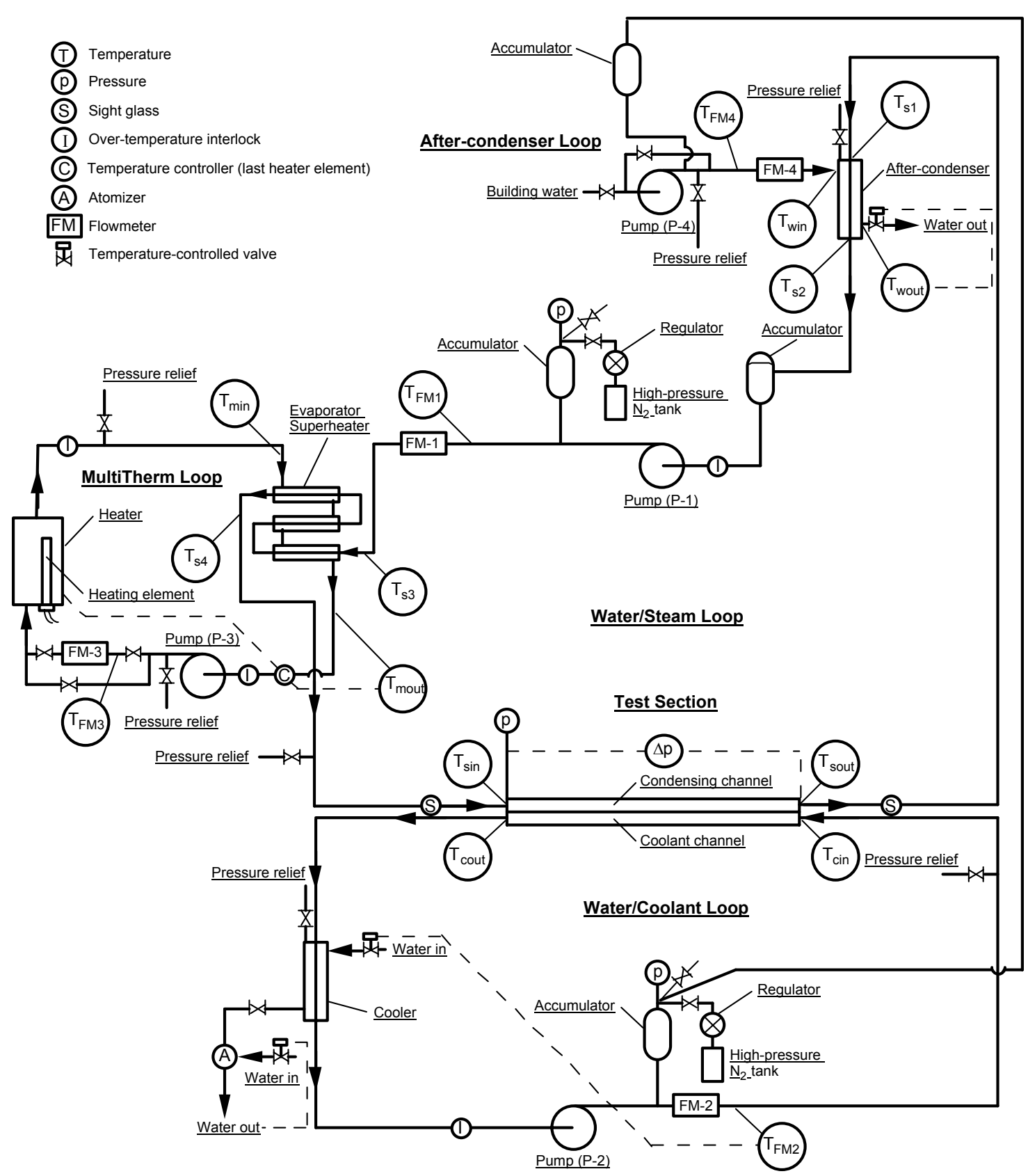

Fig. 5. Schematic representation of multiport cylinder dryer heat transfer test apparatus

MultiTherm is heated without boiling to $230^{\circ} \mathrm{C}\left(446^{\circ} \mathrm{F}\right)$ by an electrical resistance heater. The evaporator/superheater heat exchanger is of a shell-and-tube counter-flow design; it was designed with relatively small flow passages for the MultiTherm liquid, to keep its flow turbulent. Inside the evaporator/superheater, the water exchanges heat with the MultiTherm loop fluid and changes from the liquid state into saturated or slightly superheated steam, corresponding to the system pressure. The water pressure, and thus its temperature at the test section inlet, is controlled with the accumulator and high-pressure nitrogen tank shown in Fig. 5. 
Upon leaving the evaporator/superheater, the steam enters the 3-m-long (10-ft-long) test section and is condensed into subcooled water (or lower-quality steam) in the condensing channel by exchanging heat with the coolant water. The test section (shown schematically in Fig. 6) consists of a rectangular condensing channel with a cross-sectional width of $18.90 \mathrm{~mm}$ (0.75 in.) and height of $3.14 \mathrm{~mm}(0.125 \mathrm{in}$.), and a rectangular coolant channel with the crosssectional width of $18.90 \mathrm{~mm}(0.75 \mathrm{in}$.$) and height of 6.13 \mathrm{~mm}(0.25 \mathrm{in}$.). The walls of both the condensing and coolant channels are aluminum and were welded lengthwise to minimize thermal contact resistance between the two channels. Three quartz windows were included in the test section to observe and identify two-phase flow patterns and their transitions, including liquid hold-up and thickness of the condensate layer.

The facility and test section were sized to be prototypical of a cylinder dryer with a $1360 \mathrm{~kg} / \mathrm{hr}(617 \mathrm{lb} / \mathrm{hr})$ steam flow rate. Some overcapacity was designed into it to accommodate $130 \%$ condensing flow and to allow superheated inlet and subcooled water outlet at full flow. In addition, the flow rate and test section temperatures of the water coolant were designed to produce the desired condensing rates as well as to maximize experimental accuracy in determining condensing heat transfer coefficients.
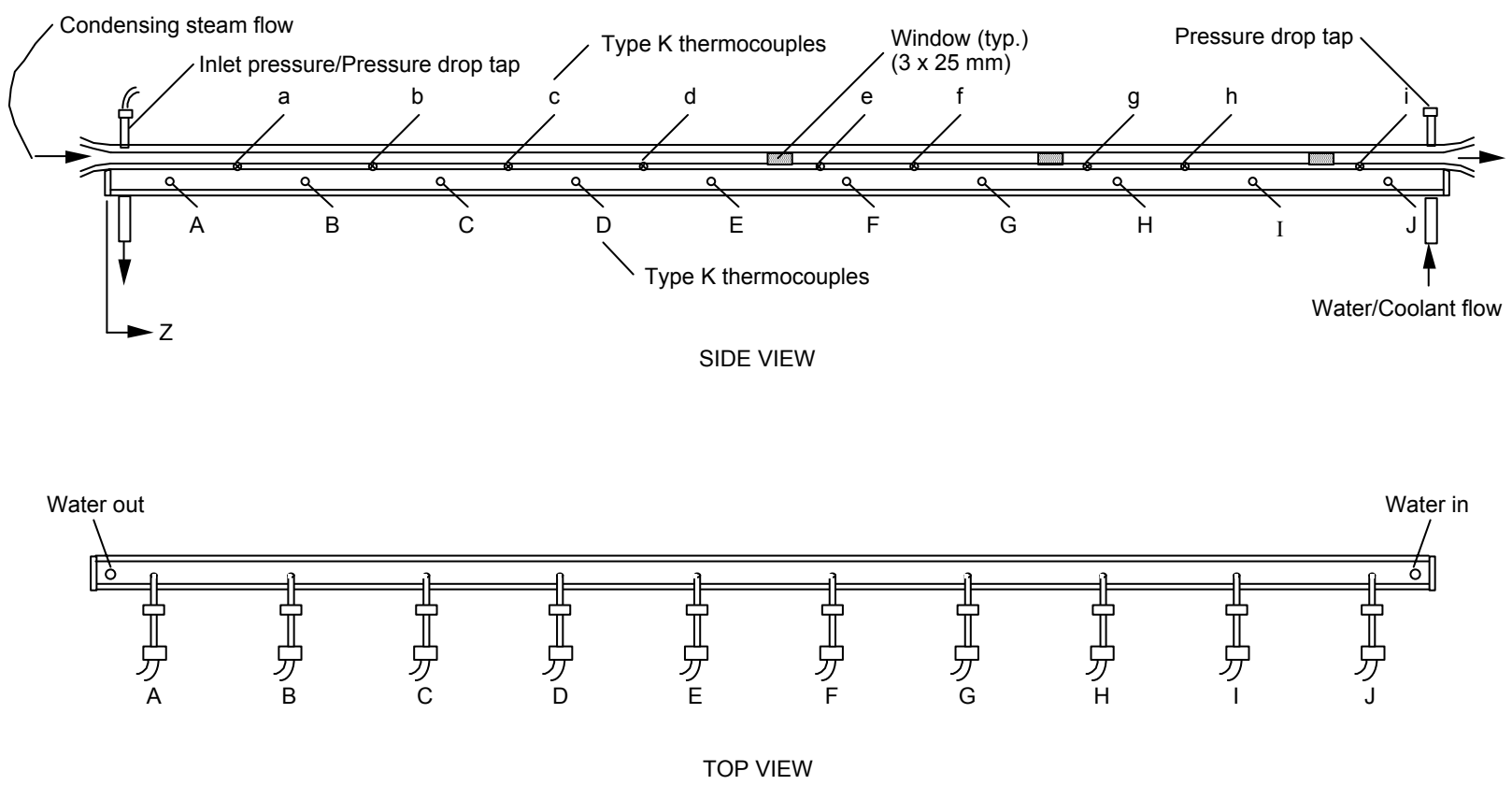

Fig. 6. Detailed schematic representation of test section 
Nine Type-K thermocouples $\left(T_{a}, T_{b}, \cdots, T_{i}\right)$ are positioned in the wall between the condensing channel and the coolant channel; they divide the test section into nine segments, each $0.305 \mathrm{~m}$ (12 in.) long. The local bulk coolant temperatures, used to calculate the local heat flux in the test section, were measured with Type-E thermocouples at 10 axial locations $\left(T_{A}, T_{B}, \cdots, T_{J}\right)$. Each stream coolant thermocouple is positioned axially between two wall thermocouples. The inlet and outlet temperatures of both the condensing and coolant channels were also measured with Type-E sheathed thermocouples in the fluid streams. These bulk temperatures made it possible to determine heat loss to the environment in single-phase tests. In condensing tests, the inlet steam pressure and overall pressure drop across the condensing channel made it possible to calculate the steam temperature distribution along the condensing channel.

Inlet steam pressure and overall pressure drop across the condensing channel were measured during experimentation. The pressure at the condensing channel inlet was measured with a piezoelectric pressure transducer (Endevco), whereas the overall condensing channel pressure drop was measured with a variable-reluctance differential pressure transducer (Validyne). The overall pressure drop, together with the pressure and temperature at the condensing channel inlet, provides a means to calculate the distribution of the steam temperature along the condensing channel. The test section is thermally well insulated to minimize heat loss to the environment.

Water exits the test section as a two-phase flow or as subcooled liquid. Subsequently it is further subcooled in the after condenser to complete the cycle.

In the water/coolant loop, Pump P-2 moves water from the cooler into the coolant channel. A turbine-type flowmeter (Flowdata) is used to measure the volumetric flow. A temperature sensor just downstream from the flowmeter provides a measure of the water temperature $T_{F M 2}$, which, in turn, allows calculation of the water density at the flowmeter and the mass flow rate. The volumetric flow can be controlled to a desired value with an AC adjustable-frequency drive.

Coolant water is used to condense steam in the test section. The coolant flow in the test section is countercurrent to the steam flow. To reject heat from the coolant that is exiting from the test section, a coolant heat exchanger, designated as Cooler in Fig. 5, was designed and fabricated with laboratory water as the heat rejection fluid. To ensure that the laboratory water would always be cool enough for disposal purposes, a mixing valve was installed downstream from the heat exchanger in the laboratory water line. This valve is equipped with a thermostatic control, and it mixes additional laboratory water with the water exiting from the heat exchanger to keep its temperature below $50^{\circ} \mathrm{C}\left(122^{\circ} \mathrm{F}\right)$. 
The test pressure of the water/coolant loop is set by the nitrogen bottle and accumulator shown in Fig. 5. The pressure was kept high enough to prevent boiling of the coolant.

The after-condenser in the after-condenser loop was designed to be used between the test section exit and the pump in the water/steam loop to fully condense and subcool the steam from the test section before pumping it. In the after-condenser loop, laboratory water enters the aftercondenser through Pump P-4. A turbine-type flowmeter (Flowdata) is used to measure the volumetric flow. A temperature sensor just upstream from the flowmeter provides a measure of the water temperature $T_{F M 4}$, which, in turn, allows calculation of the water density at the flowmeter and the mass flow rate. The volumetric flow can be controlled to a desired value by adjusting the pumping speed. This system sets the water temperature at the inlet to the evaporator/superheater. After exiting from the after-condenser, the laboratory water goes to a drain.

The pressure of the after-condenser loop is set by a nitrogen bottle and accumulator. The

pressure is set to avoid boiling of the laboratory water, and thus to maintain fine control of the water subcooling.

\section{TEST APPARATUS OPERATING PROCEDURES}

\subsection{Start-Up and Testing}

A. Preheat MultiTherm system.

Using full current on the three preheat circuits, preheat the MultiTherm system to $90-100^{\circ} \mathrm{C}$ $\left(194-212^{\circ} \mathrm{F}\right)(\approx 1 \mathrm{hr})$.

B. Turn on the data computer.

Double click the IBASIC icon. The DAS program AUTOST will run.

C. Pressurize.

While the MultiTherm is heating, pressurize as follows:

- Steam loop at 1,034 kPa (150 psi).

- Coolant loop at 1,103-1,207 kPa (160-175 psi). 
D. After-condenser heat dump.

The temperature control valve on the tap water exit from the after condenser should be set to $49^{\circ} \mathrm{C}\left(120^{\circ} \mathrm{F}\right)$, and the pump bypass valve $\mathrm{W} 1-\mathrm{V} 3$ should be partially open.

- Open the tap water valves W1-V1 and W1-V2 that supply water to the tap water pump P-4 on the after condenser, and close the throttle valve W1-V5 in series with the temperature control valve. Set the P-4 accumulator pressure to $1,103-1,207 \mathrm{kPa}(160-$ $175 \mathrm{psi})$.

- Turn on the tap water pump P-4, and adjust the throttle valve W1-V5 and pump by-pass valve to give the desired flow rate of $1,103-1,207 \mathrm{kPa}(160-175 \mathrm{psi})$. (There is a pressure gauge in the tap water system.)

E. Cooler heat dump.

Turn on the tap water flow to the cooler in the coolant loop.

- Set the tap water flow controller to give the desired coolant temperature at the test section inlet.

- Set the temperature control valve at the tap water exit to $49^{\circ} \mathrm{C}\left(120^{\circ} \mathrm{F}\right)$.

F. Activate MultiTherm pump.

After the MultiTherm temperature reaches $90^{\circ} \mathrm{C}\left(194^{\circ} \mathrm{F}\right)$, partially open the MultiTherm pump throttle valve, and turn on the MultiTherm pump P-3.

- Turn on Heater 7 and set the MultiTherm temperature to $100^{\circ} \mathrm{C}\left(212^{\circ} \mathrm{F}\right)$ as a starting point.

- Set the MultiTherm flow rate with the motor controller.

G. Turn on steam pump.

With the steam pump throttle valve cracked open, turn on the steam pump P-1, and adjust the pump throttle valve and the motor controller to give the desired flow rate with pressure drop across the throttle valve. 
H. Turn on coolant pump.

Turn on the coolant pump P-2, and adjust the motor controller to give the desired flow rate.

At this point, all five fluid systems are running at preset flow rates and pressures.

I. Activate MultiTherm heaters.

Turn on MultiTherm heaters one at a time while watching the system parameters. The number of heaters is predetermined for a given test, and Heater 7 (temperature controlled) must always be used.

J. Adjust system conditions.

Use the following adjustable parameters to maintain test conditions as follows:

- Maintain the steam flow rate at the set point, using the steam pump motor controller.

- Maintain the steam inlet temperature (to the test section) superheated at $190^{\circ} \mathrm{C}\left(374^{\circ} \mathrm{F}\right)$ by adjusting (1) the MultiTherm flow rate and (2) the MultiTherm temperature at the exit of the evaporator using the MultiTherm heater controller.

- Maintain the steam exit quality from the test section and the coolant temperature change across the test section by adjusting the coolant flow rate and the temperature setting for the coolant inlet to the test section. Lower coolant flow rates give larger temperature changes. The larger the better.

K. Maximum conditions for sustaining equipment life.

- MultiTherm temperature out of evaporator $<200^{\circ} \mathrm{C}\left(392^{\circ} \mathrm{F}\right)$

- Maximum MultiTherm temperature (at heater exit) $<249^{\circ} \mathrm{C}\left(480^{\circ} \mathrm{F}\right)$

- Steam temperature out of after condenser $<120^{\circ} \mathrm{C}\left(248^{\circ} \mathrm{F}\right)$

- Coolant temperature out of cooler $<120^{\circ} \mathrm{C}\left(248^{\circ} \mathrm{F}\right)$ 


\subsection{Shutdown}

A. Turn off all MultiTherm heaters.

B. If desired, increase fluid flow rates to increase cool-down rate.

C. When all temperatures are below $65^{\circ} \mathrm{C}\left(149^{\circ} \mathrm{F}\right)$, turn off all pumps and tap water flow.

D. Depressurize the three systems.

E. Turn off the MultiTherm preheat.

F. Turn off the computer. Note that the multiplexor always remains on.

\section{DATA ACQUISITION AND REDUCTION}

A data acquisition system (DAS), consisting of a PC (Gateway 2000) and multiplexor (Hewlett-Packard, Model HP75000), has been assembled to record data. A data acquisition program was written in Hewlett-Packard Instrument BASIC to control all measurements. The program includes all calibration equations and conversions to engineering units. The DAS provides an on-screen display of these conversions from all sensors and time charts of representative in-stream and wall-temperature measurements. These graphed signals are visually monitored to determine that steady state has been achieved. Once that determination is made, all sensor-output voltages are read 30 times by the DAS and averaged in three sets of 10 readings each. As a check on steady state, the three data sets are compared for consistency before the three results are averaged. Other pertinent information, such as inlet and outlet temperature of each heat exchanger, volumetric flow rates of each loop, steam inlet and outlet qualities of the condensing channel, and condensing-channel inlet pressure are also displayed on the screen to allow the operator to determine the validity of a given run. The final results, consisting of 30 data samples for each measured variable, are stored in the computer for future processing, as discussed below.

To define inlet quality, we start with the test section conservation of energy equation, which may be written as

$$
q_{s}=q_{c}+q_{e n v},
$$

where $q_{e n v}$ is the heat lost to the environment, $q_{c}$ is the heat used to raise the temperature of the coolant, and $q_{s}$ is the heat released from the condensing steam. 
The coolant sensible heat $q_{c}$ is calculated from the change in enthalpies of the coolant channel as

$$
q_{c}=\dot{m}_{c}\left(i_{c o u t}-i_{c i n}\right),
$$

where $m_{c}$ is the mass flow rate of the coolant, and $i_{c o u t}$ and $i_{\text {cin }}$ are, respectively, the outlet and inlet enthalpies of the coolant.

Similarly, $q_{s}$ is calculated from the change in enthalpies of the condensing channel as

$$
q_{s}=\dot{W}_{s}\left(i_{\text {sin }}+x_{i n} i_{f g}-i_{\text {sout }}\right),
$$

where $\ddot{W}_{s}$ is the mass flow rate of the steam in the condensing channel, $i_{\text {sin }}$ is the inlet enthalpy of the saturated liquid, $x_{i n}$ is the inlet quality of the steam, $i_{f g}$ is latent heat, and $i_{\text {sout }}$ is the outlet enthalpy of the condensate. In Eq. 3, it is assumed that steam enters the test channel with quality $x_{i n}$ and exits subcooled with enthalpy $i_{\text {sout }}$. Enthalpy $i_{\text {sin }}$ refers to saturated liquid where, for small pressure drops (as in this study), it is approximately constant along the condensing length. By substituting Eqs. 2 and 3 into Eq. 1, the inlet quality can be defined as

$$
x_{i n}=\frac{\dot{W_{c}}\left(i_{\text {cout }}-i_{\text {cin }}\right)+q_{e n v}-\dot{W}_{s}^{\prime}\left(i_{\text {sin }}-i_{\text {sout }}\right)}{\dot{W}_{s}^{\prime} i_{f g}} .
$$

The local condensing heat transfer coefficients may be determined as follows. By using Eq. 1, the local heat transferred from the condensing steam $\Delta q_{s}(z)$ for a particular test segment can be expressed as

$$
\Delta q_{s}(z)=\Delta q_{c}(z)+\Delta q_{e n v}(z),
$$

where $\Delta q_{e n v}(z)$ is the local heat loss and the local sensible heat of the coolant $\Delta q_{c}(z)$ is calculated from the change in local enthalpies of the coolant as follows:

$$
\Delta q_{c}(z)=\not_{c}\left[i_{c}(n)-i_{c}(n-1)\right],
$$

where the index $n$ refers to one of the nine test section segments.

Using Newton's law of cooling, we can express the local condensing heat transfer coefficient $h(z)$ as 


$$
h(z)=\frac{\Delta q_{s}(z)}{\Delta A_{s}\left[T_{s}(z)-T_{w}(z)\right]}=\frac{\Delta q_{c}(z)+\Delta q_{e n v}(z)}{\Delta A_{s}\left[T_{s}(z)-T_{w}(z)\right]},
$$

where $\Delta A_{s}$ is the heat transfer surface area of a particular test segment, and $T_{s}(z)$ and $T_{w}(z)$ are the steam and wall temperatures, respectively. It should be noted that the heat transfer surface area used to define the condensing heat transfer coefficient was set to one-half of the entire channel surface area because it represents the physical process of bottom-surface condensation, including a fin effect of the side walls of the channel. The local condensing heat transfer coefficients are evaluated at axial locations that correspond to the measurements of the wall temperature. The steam temperatures where wall temperatures are measured are calculated by using the pressure and temperature correspondence of saturating steam, which can be expressed as

$$
T_{S}(z)=f\left[p_{S}(z)\right]
$$

where $p_{s}(z)$ is the local steam pressure. Because the pressure drop across the condensing channel was small in all of our tests $(<3.5 \mathrm{kPa}[0.5 \mathrm{psi}])$, we reasonably assumed that the distribution of steam pressure over the channel length is linear. Based on the inlet steam pressure $p_{\text {sin }}$ and overall pressure drop across the condensing channel $\Delta p$, the local steam pressure $p_{s}(z)$ was approximately evaluated as

$$
p_{s}(z)=p_{\text {sin }}-\frac{\Delta p}{L} z
$$

The local quality change of the steam at a particular test segment can be expressed by using Eq. 5 to obtain

$$
\Delta q_{s}(z)=\dddot{W}_{s}[x(n-1)-x(n)] i_{f g}(z)=\Delta q_{c}(z)+\Delta q_{e n v}(z)
$$

where $i_{f g}(z)$, calculated from the local steam temperature, is the local latent heat, and $x(n-1)$ and $x(n)$ are, respectively, the inlet and outlet qualities of the steam at a particular test segment. From Eq. 10, the local quality $x(n)$ can be expressed as

$$
x(n)=x(n-1)-\frac{\Delta q_{c}(z)+\Delta q_{e n v}(z)}{\dot{m}_{s}^{\prime} i_{f g}(z)} .
$$


Based on Eqs. 1-11, a data reduction code was written in spreadsheet format with Microsoft Excel. The data reduction requires information about the thermal and transport properties of the water, saturated water/steam, and MultiTherm liquid as a function of pressure and temperature. Property data for the water, saturated water/steam, and MultiTherm liquid are based on the ASHRAE Handbook of Fundamentals [15] and on the MultiTherm IG-2 Physical Properties bulletin [16].

\section{HEAT LOSS CALIBRATION}

The inlet quality, local condensing heat transfer coefficients, and local qualities are calculated from Eqs. 4, 7, and 11, respectively. The heat loss was not negligible; therefore, its accurate characterization was important. Although the test section is well insulated to minimize heat loss to the environment, heat loss was still significant because of the low flow rates and large differences in driving temperature. The driving temperature $\Delta T_{a m b}=T_{w}-T_{a m b}$ is the temperature difference between the wall temperature $T_{w}$ and ambient temperature $T_{a m b}$. Heat loss was determined by single-phase heat transfer tests, as discussed below.

A series of single-phase heat transfer tests was performed at a condensing-channel fluid pressure of $965 \mathrm{kPa}$ (140 psi), a high flow rate, and various condensing-channel fluid inlet temperatures that ranged from ambient to $150^{\circ} \mathrm{C}\left(302^{\circ} \mathrm{F}\right)$ [the boiling temperature of water at 965 $\mathrm{kPa}(9140 \mathrm{psi})$ is $\left.178^{\circ} \mathrm{C}\left(352^{\circ} \mathrm{F}\right)\right]$. For each of the tests, heat loss was determined from the equation

$$
q_{e n v}=q_{s}-q_{c}=\mathscr{W}_{s}\left(i_{\text {sin }}-i_{\text {sout }}\right)-\mathscr{W}_{c}\left(i_{\text {cout }}-i_{\text {cin }}\right),
$$

where enthalpy $i_{\sin }$ refers to subcooled water at the inlet to the condensing channel.

The heat loss based on the single-phase heat transfer tests is plotted in Fig. 7 as a function of $\Delta T_{a m b}$; it can be expressed as a linear function of $\Delta T_{a m b}$ as follows:

$$
q_{e n v}=(h A) \Delta T_{a m b} .
$$

This linear relationship is observed in Fig. 7. In all of the condensing tests, the heat loss around the test section was $<5 \%$. 


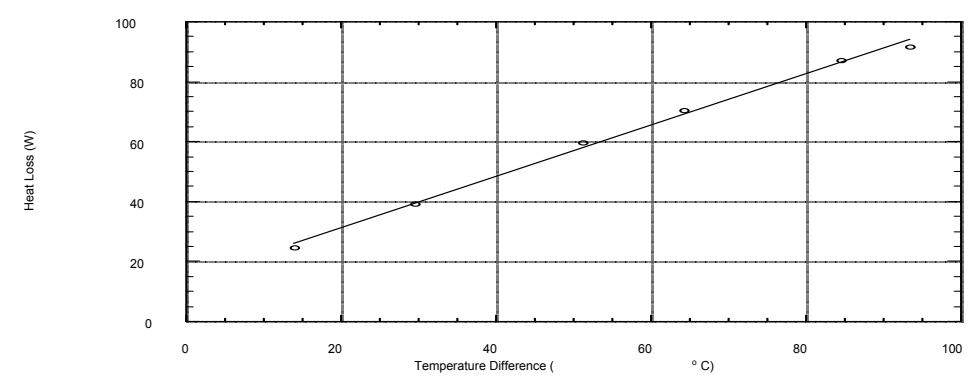

Fig. 7. Heat loss, based on single-phase heat transfer tests, as a function of temperature difference between wall and ambient

\section{EXPERIMENTAL RESULTS AND DISCUSSION}

To investigate the heat transfer characteristics of a multiport cylinder dryer channel under typical condensing conditions and to demonstrate the advantages of multiport cylinder dryers over conventional cylinder dryers, we performed a series of condensing heat transfer experiments in a specially designed multiport cylinder dryer heat transfer test apparatus. The experimental parameters are listed in Table 1.

Condensation was experimentally investigated for steam flowing in a horizontal rectangular channel, $18.90 \mathrm{~mm}$ (0.75 in.) wide, $3.14 \mathrm{~mm}$ (0.125 in.) high, and $3 \mathrm{~m}$ (10 ft.) cooled length. A series of condensing tests was performed over a range of mass flux of $20-49 \mathrm{~kg} / \mathrm{m}^{2} \mathrm{~s}$ $\left(4.1 \mathrm{lb} / \mathrm{ft}^{2} \mathrm{~s}-10.1 \mathrm{lb} / \mathrm{ft}^{2} \mathrm{~s}\right)$, pressure of $170-620 \mathrm{kPa}(25-90 \mathrm{psia})$, and quality of 0.1-0.8. We have focused condensing heat transfer tests on the effects of mass flux, pressure, and quality on the characteristics of condensing heat transfer. Also we have measured the two-phase pressure gradient as a function of mass flux, and wall temperature as a function of axial location. In each test, local values of the condensing heat transfer coefficient and quality were determined at measurement points along the test section. 
Table 1. Value/range of experimental parameters

\begin{tabular}{ll}
\hline Parameter & Tested range \\
\hline Flow channel & Rectangular channel \\
Flow direction & Horizontal \\
Hydraulic diameter, mm & 10.8 \\
Maximum condensing length, $\mathrm{m}$ & 2.87 \\
Steam temperature, ${ }^{\circ} \mathrm{C}$ & $115-160$ \\
Quality, $\%$ & $10-80$ \\
Heat flux, $\mathrm{kW} / \mathrm{m}^{2}$ & $11.6-201$ \\
Mass flux, $\mathrm{kg} / \mathrm{m}^{2} \mathrm{~s}$ & $20-50$ \\
Pressure, $\mathrm{kPa}$ & $170-620$ \\
Reynolds number of liquid & $910-2970$ \\
Prandtl number of liquid & $1.09-1.52$ \\
\hline
\end{tabular}

Uncertainties for experimental results were determined by using the method of sequential perturbation, as outlined by Moffat [17] for single-sample data. Uncertainties in each of the independent variables used to calculate the heat transfer coefficient were estimated on the basis of calibration and examination of system/sensor interaction errors. The uncertainties are $<7 \%$ for the experimental condensing heat transfer coefficients.

Ultrahigh Condensing Heat Transfer Coefficients. The average condensing heat transfer coefficient is plotted as a function of mass flux in Fig. 8. The scatter in the plotted data is due in part to the influence of the other parameters (quality and pressure) that varied among these tests. It is important to note the high values of the condensing heat transfer coefficients for Multiport dryers, which are on the order of $15,000 \mathrm{~W} / \mathrm{m}^{2} \mathrm{~K}\left(2600 \mathrm{Btu} / \mathrm{hr} \mathrm{ft}{ }^{20} \mathrm{~F}\right)$. The heat transfer surface area used in the definition of the heat transfer coefficient was set to the actual heat transfer area (as opposed to the entire channel circumference) which produces a coefficient that most represents the physical process and is the one that would be used in the design of an MD for industry.

Mass Flux Effect. It can be seen in Fig. 8 that the condensing heat transfer coefficient is approximately independent of flow rate. Condensing correlation equations for larger tubes generally predict that the condensing heat transfer coefficient increases at higher flow rates, but this condition was not observed in our study. This flow-rate-independent result was observed previously in condensing tests performed at ANL with refrigerants at low mass fluxes down to $100 \mathrm{~kg} / \mathrm{m}^{2} \mathrm{~s}\left(73,734 \mathrm{lb} / \mathrm{ft}^{2} \mathrm{hr}\right.$ ). (The flow-rate dependence was observed at higher mass flow rates.) In the present tests, all mass fluxes were $<100 \mathrm{~kg} / \mathrm{m}^{2} \mathrm{~s}\left(73,734 \mathrm{lb} / \mathrm{ft}^{2} \mathrm{hr}\right)$ and ranged from $20 \mathrm{~kg} / \mathrm{m}^{2} \mathrm{~s}\left(14,747 \mathrm{lb} / \mathrm{ft}^{2} \mathrm{hr}\right)$ to $50 \mathrm{~kg} / \mathrm{m}^{2} \mathrm{~s}\left(36,867 \mathrm{lb} / \mathrm{ft}^{2} \mathrm{hr}\right)$. 


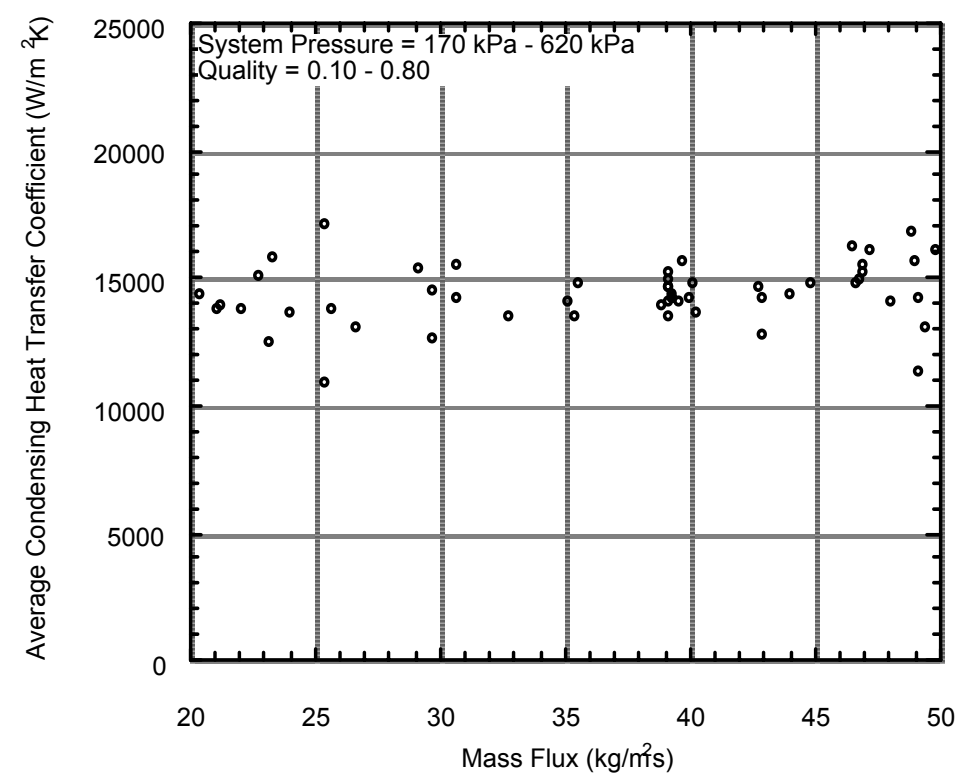

Fig. 8. Average condensing heat transfer coefficients as function of mass flux

Pressure Effect. In Fig. 9, the average condensing heat transfer coefficient for each test is plotted as a function of the system pressure. It can be seen that the condensing heat transfer coefficient is also approximately independent of system pressure over the experimental range of $170-620 \mathrm{kPa}(25-90 \mathrm{psi})$.

Quality Effect. Figure 10, which is a plot of the local condensing heat transfer coefficients as a function of quality in a representative multiport channel, shows that the heat transfer coefficient is approximately constant as quality changes over the experimental range of 0.8-0.1. This trend was also observed previously in ANL condensing tests with refrigerants at low flow rates. Although the heat transfer coefficient gradually reduces with the decrease of the quality from 0.80 to 0.10 , the reduction is not large. In fact, the results of wall-temperature measurements demonstrate that very good uniformity of cylinder wall temperature distribution can be achieved with multiport cylinder dryer technology (see Fig. 11). Thus our experimental data would suggest that at low steam flow rates there will not be a tendency for a wet streak to develop in the sheet at one end of the dryer cylinder.

Pressure Gradient. Figure 12 shows the two-phase pressure gradient as a function of mass flux. The test section pressure gradient is shown to be relatively low, primarily because of the low mass flow range of operation in multiport cylinder dryers. This means that for a 10-m (32.8$\mathrm{ft}$ )-wide dryer shell and a mass flux of $50 \mathrm{~kg} / \mathrm{m}^{2} \mathrm{~s}\left(36,867 \mathrm{lb} / \mathrm{ft}^{2} \mathrm{hr}\right)$, the total pressure drop would be $\approx 15 \mathrm{kPa}(2.2 \mathrm{psi})$. This is less than the maximum acceptable value of $27.6 \mathrm{kPa}(4.0$ psi) for cylinder dryers. These low pressure-gradient values translate into almost negligible change in saturation temperature along the channels of multiport cylinder dryers. (Note that the data scatter in Fig. 12 is a quality effect that is not taken into account in the figure.) 


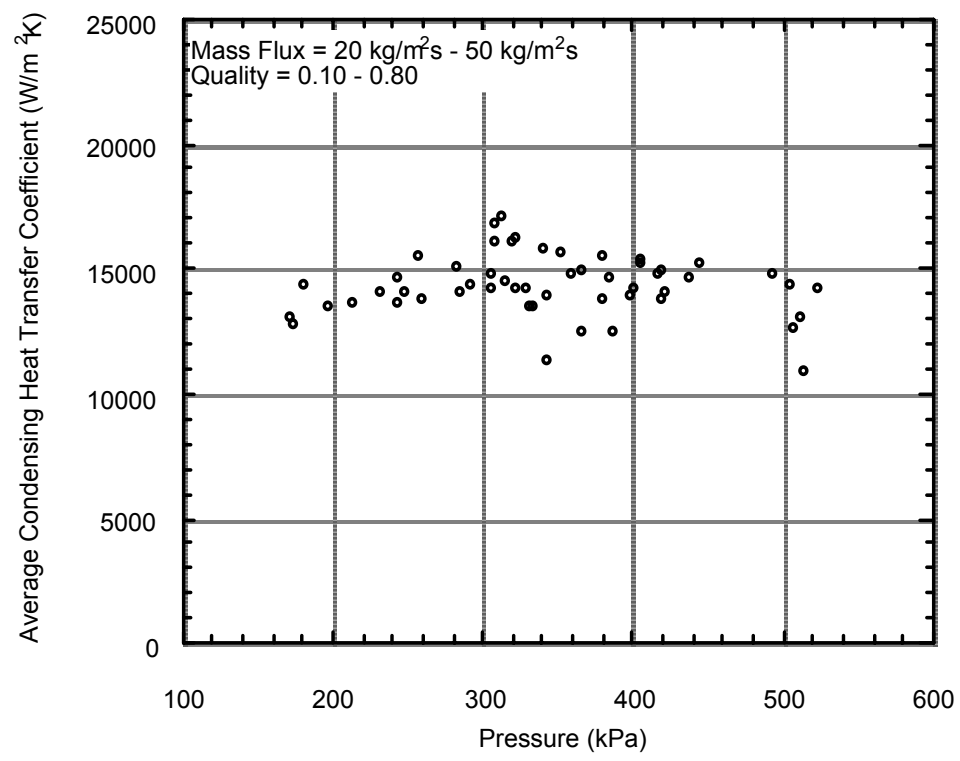

Fig. 9. Average condensing heat transfer coefficients as function of pressure

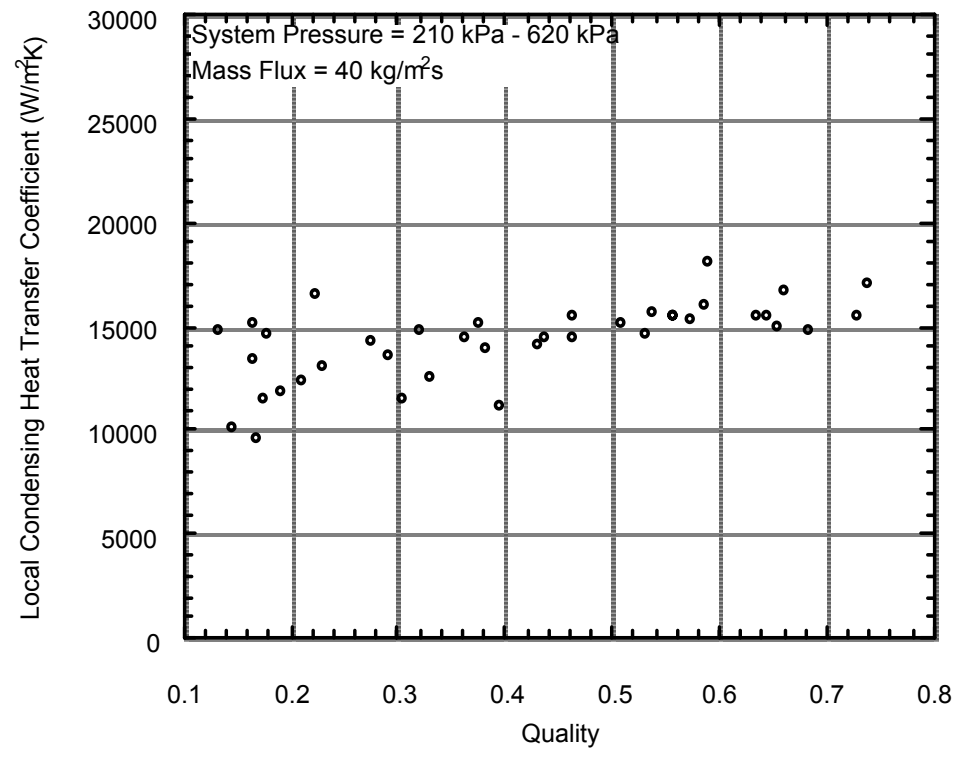

Fig. 10. Local condensing heat transfer coefficients as function of quality 


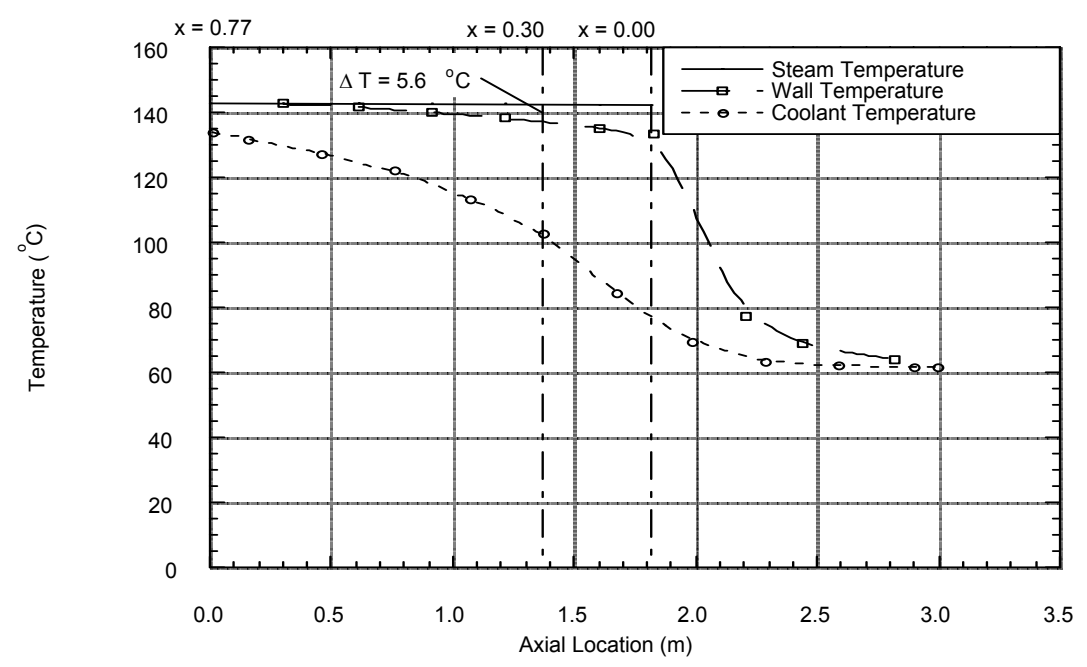

Fig. 11. Temperature distribution

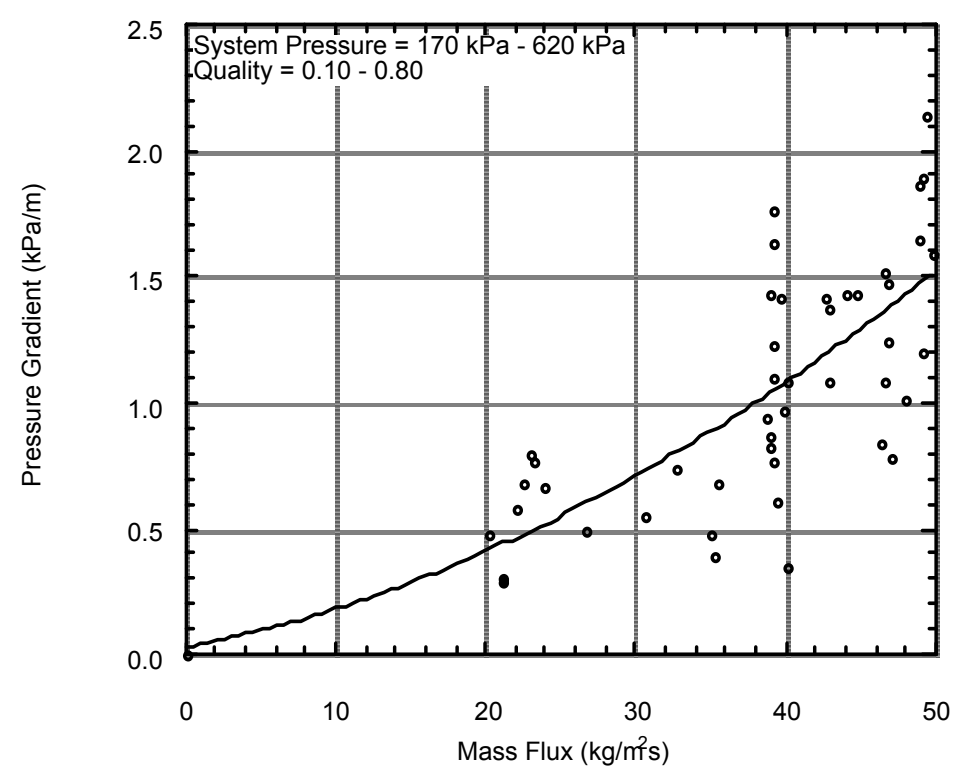

Fig. 12. Two-phase pressure gradient as function of mass flux 
Wall Temperature Distribution. A typical plot of wall temperature, steam temperature, and coolant temperature distribution is given in Fig. 11. Three parameters contribute to ensuring the uniformity of dryer wall temperature: high condensing heat transfer coefficients, condensing heat transfer coefficients approximately independent of quality, and low steam pressure drop to maintain a near-constant saturation temperature. As noted, all three of these criteria have now been demonstrated in our current experimental results. Together, they ensure the temperature uniformity needed in cylinder dryer applications. A numerical simulation of the MD was conducted to provide axial distributions of temperature and condensate layer thickness. The results also show a near-uniform dryer surface temperature profile and a very thin condensate layer on the order of $0.1 \mathrm{~mm}(0.004 \mathrm{in}$.).

\section{POTENTIAL BENEFITS}

\subsection{Comparison with Conventional Cylinder Dryers}

The condensing heat transfer coefficients in a multiport cylinder dryer can be compared directly with those from steam condensation in conventional dryers with or without spoiler bars. The values for Multiport dryers are $\approx 15,000 \mathrm{~W} / \mathrm{m}^{2} \mathrm{~K}\left(2600 \mathrm{Btu} / \mathrm{hr} \mathrm{ft}^{20} \mathrm{~F}\right)$. In the conventional case, for an overall heat transfer coefficient of $328 \mathrm{~W} / \mathrm{m}^{2} \mathrm{~K}\left(58 \mathrm{Btu} / \mathrm{hr} \mathrm{ft}{ }^{20} \mathrm{~F}\right.$, fine paper), the base value for the condensing heat transfer coefficient in a dryer without spoiler bars ranges from 665 to $850 \mathrm{~W} / \mathrm{m}^{2} \mathrm{~K}$ (117 to $150 \mathrm{Btu} / \mathrm{hr} \mathrm{ft}^{20} \mathrm{~F}$ ). The base value for the condensing heat transfer coefficient in a conventional dryer with spoiler bars is $2270 \mathrm{~W} / \mathrm{m}^{2} \mathrm{~K}\left(400 \mathrm{Btu} / \mathrm{hrft}{ }^{20} \mathrm{~F}\right)$ $[7,18]$. As shown in Fig. 13, the condensing heat transfer coefficient in the multiport cylinder dryer is $\approx 7$ times greater than that in a conventional dryer with spoiler bars, and $\approx 20$ times greater when compared with that in a conventional dryer without spoiler bars. This very large improvement in heat transfer coefficient for multiport cylinder dryers when compared with conventional dryers is the key to the increased efficiency of the heat transfer process in multiport cylinder dryers.

\subsection{Potential Benefits and Impacts}

Multiport dryer technology will provide the following attractive benefits and impacts:

- Increased drying rate or increased productivity, a major impact of the multiport cylinder dryer technology on the paper production industry, comes from the potential to increase paper drying rates or production rates in existing machines. An increase in drying rate can be viewed in two ways. The number of dryers can be reduced while paper production rate remains the same, or alternatively, system speed can be increased 
to produce paper at a higher rate with the same number of dryers. In the latter case,

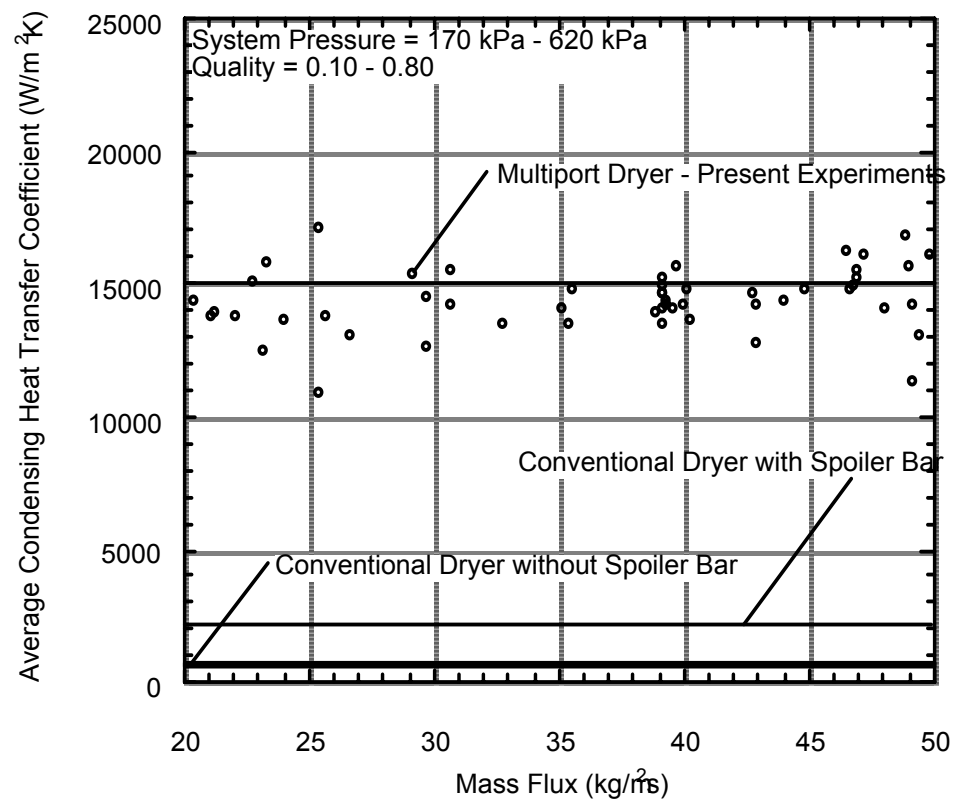

Fig. 13. Average condensing heat transfer coefficients of multiport and conventional cylinder dryers

current experimental data show that multiport cylinder dryers can potentially increase paper drying or production rates by as much as $20 \%$ when compared with spoiler bar technology, and by as much as $90 \%$ when compared with existing technology without spoiler bars (see Fig. 14). These increases were estimated by using an overall heat transfer coefficient of $256 \mathrm{~W} / \mathrm{m}^{2} \mathrm{~K}\left(45 \mathrm{Btu} / \mathrm{hr} \mathrm{ft}^{20} \mathrm{~F}\right)$ for the conventional cylinder dryers without spoiler bars and the best overall heat transfer coefficient of $328 \mathrm{~W} / \mathrm{m}^{2} \mathrm{~K}$ $\left(58 \mathrm{Btu} / \mathrm{hr} \mathrm{ft}{ }^{20} \mathrm{~F}\right.$ ) for the conventional cylinder dryers with spoiler bars. Production rate increases were estimated with results from the single-tube, nonrotating test channel for multiport cylinder dryers and average results from the engineering literature for conventional cylinder dryers with and without spoiler bars. Some of the practical effects of a prototype or full-scale model multiport cylinder dryer are not yet known. Therefore, there is a need to conduct MD performance tests in a full-scale, rotating test dryer to evaluate the concept under prototypical condition. Consequently, these increased production rate estimates should be viewed as idealized target levels.

- Uniform dryer surface temperature can be attained because multiport dryer technology provides a highly uniform distribution of cylinder-wall temperature, which is the result of high condensing heat transfer coefficients, together with condensing heat transfer 
coefficients that are approximately independent of quality and low steam pressure drop to maintain near-constant saturation temperature. Uniformity of dryer surface temperature is essential for a uniform moisture profile.

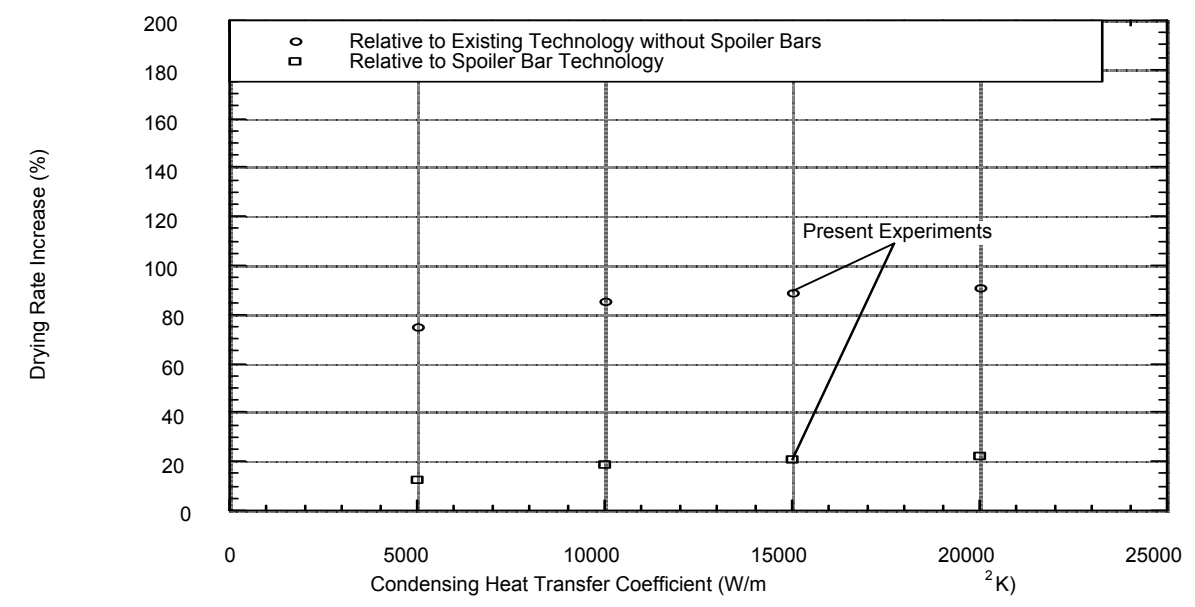

Fig. 14. Increased drying rate as a result of multiport technology

- Energy savings, based on the analysis presented in the Appendix, can be realized for several reasons. (1) Multiport dryer technology can be used to increase productivity, or alternatively, it will allow the use of lower operating steam pressure while maintaining the same paper production rate. The lower-pressure, lower-temperature steam system would provide energy savings from lower heat losses in steam transmission and condensate return lines, lower heat losses at the dryer heads, and smaller leak rates. Also, less blow-through steam is required at low pressures. For retrofits, we have estimated that $3.5 \%$ less steam would be consumed by a MD than by the current dryer technology. Therefore, for paper and paperboard production, the MD technology could potentially save $>6.6$ trillion Btu/year by 2010 and $>16.6$ trillion Btu/year by 2020. (2) Increased production capacity will delay the need to build new plants, and thus save the energy associated with manufacturing new dryers. These energy savings must be estimated. (3) In a MD, condensate removal will be facilitated and condensate load will be minimized, leading to drive-power savings. Quantification of these savings would require a much more detailed analysis of the entire dryer system.

- Increased environmental benefits will follow, because the energy savings mentioned above will lead to reductions in greenhouse gas emissions. The estimated decreases in $\mathrm{CO}_{2}$ emissions, as indicated by the analysis in the Appendix, are 0.6 million tons/year by 2010 and 1.6 million tons/year by 2020. This analysis, performed for paper and paperboard production of 80 million tons per year, projects that the first industrial prototypes of the MD technology would be installed in 2000 and would then increase to 
a steady-state market penetration rate. The market penetration rate used for the retrofit case is $3 \%$ per year, based on the number of old-style dryers still in service.

- Existing cylinder dryers may be inexpensively modified to include the simple multiport concept. The capital required to retrofit existing dryers would be much lower than that needed to purchase new dryers. The estimated cost of a retrofit module will be less than one-fifth that of a new dryer. Therefore, multiport dryer technology offers a new and innovative way to produce more paper at lower capital cost.

- For new plants, the new technology makes cylinder dryers economical in smaller sizes because the diameter of the new dryer is estimated to be $50 \%$ or less of that of a conventional dryer for the same paper production rate. Hence, new construction will be less expensive.

- The increased productivity or downsized dryer section translates directly into significant improvements in capital effectiveness and financial performance of the country's most capital-intensive industry.

- The increased drying rates will enable increased machine speed or elimination of several existing dryers, providing space for a new press section. For new applications it is estimated that the new dryers will require only $\approx 60 \%$ as much floor space as conventional equipment.

- Increased drying rates will lead to increased dryer speed. Multiport dryer technology, when used for new dryer applications, will play an important role in realizing the vision of advanced papermaking technologies, including high-speed machines of the future.

- From the benefits mentioned above, it follows that multiport dryer technology could significantly enhance the global competitiveness of the North American forest products industry.

\section{FUTURE WORK AND EXPECTED RESULTS}

Recently, the Capital Effectiveness Task Group of the American Forest and Paper Association has identified the research areas of greatest potential value to the industry. Specifically, they identified drying rate as having the second-greatest significance to the longterm success of the industry with a goal of $0.0136 \mathrm{~kg} \mathrm{H} \mathrm{H}_{2} \mathrm{O} / \mathrm{s} / \mathrm{m}^{2}\left(10 \mathrm{lb} \mathrm{H} \mathrm{H}_{2} \mathrm{O} / \mathrm{hr} / \mathrm{ft}^{2}\right)$. It will be impossible to reach this rate with only an incremental improvement in current drying technology. The industry needs a genuine breakthrough that can double the current drying rate of 
$0.0068 \mathrm{~kg} \mathrm{H} \mathrm{H}_{2} \mathrm{O} / \mathrm{s} / \mathrm{m}^{2}\left(5 \mathrm{lb} \mathrm{H} \mathrm{H}_{2} \mathrm{O} / \mathrm{hr} / \mathrm{ft}^{2}\right)$ in order to reach the goal and to increase machine speed by a factor of 2 or 3 . This goal provides a true challenge to the forest products industry.

With the feasibility of the concept already proved in ANL's unique MD Heat Transfer Test Facility, the next step is to continue the project to full-scale tests. Our proposal to continue the project for full-scale demonstration was accepted and Phase 2 (FY 01-03) is in progress. In Phase 2 of the MD project, we plan to conduct prototype tests to demonstrate that the MD technology is an innovative approach to improve productivity and can be retrofitted cost effectively. The following work will be performed in Phase 2.

- Complete laboratory-scale tests by expanding the test envelope to high-quality inlets (0.8-1.0).

- With the extensive data base, develop reliable design correlations for condensing heat transfer and two-phase pressure drop in MDs. Such correlations are necessary for prototype design and future implementation of MDs to the pulp and paper industry.

- Design and fabricate a prototype multiport cylinder dryer to be tested in one of the research dryers at the Johnson Corporation's R\&D Center. Johnson will conduct prototype tests, compare the performance of dryers with and without multiport passages as a function of key parameters, including steam flow rate, system pressure, and rotating speed, and evaluate the MD concept for commercialization.

- Work with Eastern will assess the economic feasibility of implementing the multiport technology for typical small and large plants, including estimated savings in capital costs.

- Prepare a final report that documents the performance of MD technology, including critical design information needed for the technology to work.

ANL's successful pilot MD demonstration will lead to ultimate commercialization by the industry.

\section{CONCLUSIONS}

Argonne National Laboratory has developed an MD design concept that could create breakthroughs in drying pulp and paper. Experimental studies were undertaken in ANL's MD Heat Transfer Test Facility. In proof-of-concept tests we have shown that 
- The condensing heat transfer coefficient of the multiport cylinder dryer, which is $\approx 15,000 \mathrm{~W} / \mathrm{m}^{2} \mathrm{~K}\left(2600 \mathrm{Btu} / \mathrm{hr} \mathrm{ft}{ }^{20} \mathrm{~F}\right)$, is larger than that of conventional dryers by a factor of between 7 and 20, depending on whether a conventional dryer employs or does not employ spoiler bars.

- The two-phase pressure gradient of the multiport cylinder dryer is relatively low, due primarily to the low mass flow range of operation of the dryer. For a $10-\mathrm{m}(32.8 \mathrm{ft})-$ wide dryer shell and a mass flux of $50 \mathrm{~kg} / \mathrm{m}^{2} \mathrm{~s}\left(36,867 \mathrm{lb} / \mathrm{ft}^{2} \mathrm{hr}\right)$, the total pressure drop would be $\approx 15 \mathrm{kPa}(2.2 \mathrm{psi})$, which is less than the maximum acceptable value of $27.6 \mathrm{kPa}(4.0 \mathrm{psi})$ for cylinder dryers.

- Because of the small size of the condensing channel and the low mass flow range of operation of the multiport cylinder dryer, the condensing heat transfer coefficient of the dryer is approximately independent of flow rate, system pressure, and quality.

- All of the above factors ensure good uniformity of dryer wall temperature. This uniformity has been confirmed by the results of wall-temperature measurements.

- Using the results we obtained to estimate an overall thermal resistance we found that multiport cylinder dryers can potentially increase paper drying or production rates by as much as $20 \%$ when compared with spoiler bar technology, and by as much as $90 \%$ when compared with existing technology without spoiler bars. These findings translate into either a reduction in the number of dryers with the same production or an increased production rate with the same number of dryers.

The laboratory-scale tests in Phase 1 of the MD project show that this new MD would provide significant benefits over existing technology, including the fact that retrofitting of existing cylinder dryers with MD technology will improve productivity, capital effectiveness, energy efficiency, competitiveness, and environmental performance.

The major milestone of phase 1 of the MD project is the successful demonstration of the feasibility of the concept of MD in laboratory-scale tests. However, the practical effects of a full-scale model MD are still unknown; thus, performance tests in a full-scale, rotating test dryer will be conducted in Phase 2 to demonstrate that the dryer can be used to retrofit existing dryers. In Phase 2 of the project, a prototype dryer will be designed, built, installed, and tested in a pilot dryer. After collecting data on the operation of the pilot machine, the technology will be transferred to dryer equipment suppliers to prepare it for the commercial market. With Johnson and Eastern as partners, the transfer of the technology to industry will be facilitated. Phase 2 of the project is expected to be completed by September 2003. 


\section{ACKNOWLEDGMENTS}

This work was supported by the U.S. Department of Energy (DOE), Office of Energy Efficiency and Renewable Energy, Office of Industrial Technologies, under Contract W-31-109Eng-38. The authors thank Valri Robinson of DOE for support of this work and Roger K. Smith for his contributions in fabricating the test apparatus, fabricating and instrumenting the test channel, and calibrating the instrumentation.

\section{REFERENCES}

[1] M. W. Wambsganss, J. A. Jendrzejczyk, and D. M. France, Two-Phase Flow Patterns and Transitions in a Small, Horizontal, Rectangular Channel, Int. J. Multiphase Flow, Vol. 17, No. 3, pp. 327-342, 1991.

[2] Y.S. Cha, J. R. Hull, and U. S. Choi, Cryostabilization of High-Temperature Superconducting Magnets with Subcooled Flow in Microchannels, IEEE Trans. Appl. Supercond., Vol. 3, No. 1, pp. 172-176, 1993.

[3] U. S. Choi, C. S. Rogers, and D. M. Mills, High-Performance Microchannel Heat Exchanger for Cooling High-Heat-Load X-ray Optical Elements, in Micromechanical Systems, eds. D. Cho, J. P. Peterson, A. P. Pisano, and C. Friedrich, The American Society of Mechanical Engineers, New York, DSC-Vol. 40, pp. 83-89 (Nov. 1992). Also presented at the ASME Winter Annual Meeting, Anaheim, CA, November 8-13, 1992.

[4] S. U. Choi, W. Yu, D. M. France, and M. W. Wambsganss, A Novel Multiport Cylinder Dryer, TAPPI Journal, Vol. 84, No. 2, p. 47, 2001.

[5] R. D. Wiedenbeck, Steam Heated Dryers, in Practical Aspects of Pressing and Drying, 1986 Short Course Notes, TAPPI Press, Atlanta, pp. 221-229, 1986.

[6] G. L. Wedel, Spoiler Bars, in Practical Aspects of Pressing and Drying, 1986 Short Course Notes, TAPPI Press, Atlanta, pp. 207-212, 1986.

[7] J. H. Pulkowski and G. L. Wedel, Effect of Spoiler Bars on Dryer Heat Transfer, Pulp \& Paper Canada, Vol. 89, No. 8, pp. 61-66, 1988.

[8] D. W. Appel and S. H. Hong, Condensate Distribution and Its Effects on Heat Transfer in Steam-Heated Dryers, Pulp and Paper Magazine of Canada, Vol. 70, No. 2, pp. 66-77, 1969. 
[9] J. C. Y. Wang, L. J. Qiu, and S. F. Wang, Enhanced Condensation inside a Horizontal Rotating Drum-drier, Drying Technol., Vol. 8, No. 4, pp. 829-843, 1990.

[10] S. Stenstrom, A General Model for Calculating Pressure Drop in Siphons and Siphon Riser Tubes - Part 1: Principles and Theoretical Model, TAPPI Journal, Vol. 74, No. 11, pp. 154-160, 1991.

[11] S. Stenstrom, A General Model for Calculating Pressure Drop in Siphons and Siphon Riser Tubes - Part 2: Experimental Results, TAPPI Journal, Vol. 74, No. 12, pp. 157-162, 1991.

[12] D. B. Hall, J. F. Monroe, and G. L. Timm, Application of Stationary and Rotary Siphons, TAPPI Journal, Vol. 76, No. 8, pp. 97-105, 1993.

[13] D. W. Appel and S. H. Hong, Optimising Heat Transfer Using Bars, Paper Technol. and Industry, Vol. 16, No. 4, pp. 264-269, 1975.

[14] D. L. Calkins, The Effects of Syphon Clearance on Dryer Performance, Johnson Technical Papers, The Johnson Corp., Three Rivers, MI, 1992.

[15] ASHRAE Handbook of Fundamentals, ASHRAE, Inc., Atlanta, 1993.

[16] MultiTherm IG-2 Physical Properties Bulletin, MultiTherm Corp., Colwyn, PA, 1994.

[17] R. J. Moffat, Describing the Uncertainties in Experimental Results, Exptl. Thermal and Fluid Sci., Vol. 1, p. 1, 1988.

[18] A. S. Mujumdar, Ed., Handbook of Industrial Drying, 2nd edn., Marcel Dekker, New York, p. 867, 1995. 


\title{
APPENDIX
}

\section{Energy Savings and Waste Reduction Analysis for the Multiport Dryer Technology}

\author{
by \\ John Harkness
}

The Multiport Dryer technology could potentially save more than 7.1 trillion Btu/year by the year 2010 and more than 17.9 trillion Btu/year by the year 2020. The corresponding decreases in $\mathrm{CO}_{2}$ emissions are 0.67 and 1.68 million tons/year, respectively. Most of these savings come from paper and paperboard production with less than $10 \%$ attributable to market pulp production.

These savings are the minimum savings to be expected since they were derived exclusively from the decrease in steam consumption made possible by the enhanced heat-transfer coefficient of the new Multiport Dryer design. Perhaps there would also be some savings in electrical usage but quantifying these would require a much more detailed analysis of the entire dryer system. These savings were calculated for two scenarios-retrofit of existing dryers and new dryer installations. In the retrofit scenario, I assumed that the heat-transfer coefficient improved by a factor of two while, in the new dryer scenario, an improvement by a factor of three was assumed. I used this information to calculate the energy savings per "standard" dryer (at 5,000 tons/year/dryer) which I then extrapolated to the national energy savings using the industry data provided by Eastern Pulp and Paper. Eastern also provided a detailed distribution of fuel sources which was used to calculate the decrease in $\mathrm{CO}_{2}$ emissions based upon the emission factors published in the $\mathrm{NICE}^{3}$ solicitation. The industry data were also used to calculate the annual installation of new dryers based on an expected growth rate of $2.5 \%$ (G. Stanley, TAPPI Journal, Vol. 81: No. 1, pp. 35-42, January 1998). Also, note that the expected energy savings would be greater if some of the old dryers were replaced with new dryers instead of being retrofitted.

Since the total amount of water evaporated from a ton of paper product is the same regardless of the dryer technology, energy can be saved only if the drying operation can be conducted more efficiently with the new Multiport Dryer technology. For retrofits, 3.45\% less steam would be consumed by a Multiport Dryer than by the current dryer technology. For new dryer installation, we estimated a $4.55 \%$ decrease in steam consumption for the Multiport Dryer technology. In addition to these direct energy savings, the lower-temperature, lower-pressure steam system would also have indirect savings from lower heat losses in steam transmission and hot-water return lines, lower heat losses at the dryer heads, smaller leak rates because of the lower system pressures, and more efficient steam generation because of the ability to extract 
more of the available energy from the fuel source. I believe these secondary benefits would, conservatively, double the direct energy savings described above.

The attached spreadsheets detail the expected slow, but steady, market penetration by the Multiport Dryer technology assuming that the improvements in the dryer heat-transfer coefficients are realized. The first page is the market penetration spreadsheet for paper and paperboard production (about 80 million tons per year in 1996) and the third page is for market pulp production (about 8 million tons per year in 1996). The second and fourth pages itemize the data and assumptions used for the market penetration analyses. This analysis projects that the first industrial prototypes of the Multiport Dryer technology would be installed in the year 2000 and would then build up over a five-year period to a steady state market penetration rate. The market penetration rate used for the retrofit case is 3\% per year based on the number of the old-style dryers still in service and $25 \%$ per year for the new dryer installation. The higher rate for the new installations is justified by the added costs incentives of installing a lower pressure steam system. The "total new" and "total retro" columns show the accumulated number of dryers installed for each scenario while the "total" column is just the sum of these two columns. Finally, the "Market penetration" column is the total column divided by the "Number of cylinder dryers in service" column.

The final two columns summarize the annual energy savings and decreased $\mathrm{CO}_{2}$ emissions, respectively. The values for dryer retrofits and new dryer installations are shown separately. The sum of the annual savings for the two scenarios are calculated for the years 2010 and 2020. These calculations are summarized in Table A1. 


\section{Market Penetration, Energy Savings, and $\mathrm{CO}_{2}$ Decrease for Multiport Dryer Technology}

\begin{tabular}{|c|c|c|c|c|c|c|c|c|c|}
\hline & 80.0 & \multicolumn{4}{|c|}{ million tons paper per year yields } & \multirow{3}{*}{2.50} & & & \\
\hline & \multicolumn{2}{|c|}{ at 5,000 t/yr/dryer } & \multirow{2}{*}{$\frac{17,920}{\text { ler dryers }}$} & \multirow{2}{*}{\multicolumn{2}{|c|}{ dryers in service }} & & \multicolumn{3}{|c|}{$\%$ growth per year } \\
\hline & $90 \%$ & are cylinder dryers & & & & & & & \\
\hline & $\begin{array}{l}\text { Number } \\
\text { of } \\
\text { cylinder } \\
\text { dryers }\end{array}$ & \multicolumn{5}{|c|}{ Calculations for Paper and Paperboard } & $\begin{array}{l}\text { Market } \\
\text { penetra- } \\
\text { tion }\end{array}$ & $\begin{array}{l}\text { Energy } \\
\text { Savings }\end{array}$ & $\begin{array}{l}\text { Decreased } \\
\mathrm{CO}_{2} \\
\text { Emissions }\end{array}$ \\
\hline & in service & & & & & & $\begin{array}{c}\% \text { of } \\
\text { dryers }\end{array}$ & $10^{12} \mathrm{Btu} / \mathrm{yr}$ & $10^{6}$ tons $/ \mathrm{yr}$ \\
\hline & & 25.00 & & 3.00 & & & & & \\
\hline & & new & total new & retrofit & $\begin{array}{l}\text { total } \\
\text { retro }\end{array}$ & total & & \multicolumn{2}{|c|}{$\begin{array}{l}\text { Savings for Retrofit } \\
\text { Dryers }\end{array}$} \\
\hline 1996 & 16,128 & 0 & & 0 & & & $0.00 \%$ & 0.0013455 & 125.70 \\
\hline 1997 & 16,531 & 0 & & 0 & & & $0.00 \%$ & $10^{12} \mathrm{Btu} / \mathrm{yr}$ & tons/yr \\
\hline 1998 & 16,944 & 0 & & 0 & & & $0.00 \%$ & per dryer & per dryer \\
\hline 1999 & 17,368 & 0 & & 0 & & & $0.00 \%$ & & \\
\hline 2000 & 17,802 & 1 & 1 & 2 & 2 & 3 & $0.02 \%$ & & \\
\hline 2001 & 18,247 & 12 & 13 & 20 & 22 & 35 & $0.19 \%$ & \multicolumn{2}{|c|}{ Savings for New Dryers } \\
\hline 2002 & 18,704 & 25 & 38 & 50 & 72 & 110 & $0.59 \%$ & 0.0017745 & 165.78 \\
\hline 2003 & 19,171 & 50 & 88 & 100 & 172 & 260 & $1.36 \%$ & $10^{12} \mathrm{Btu} / \mathrm{yr}$ & tons/yr \\
\hline 2004 & 19,650 & 119 & 207 & 200 & 372 & 579 & $2.95 \%$ & per dryer & per dryer \\
\hline 2005 & 20,142 & 122 & 329 & 400 & 772 & 1,101 & $5.47 \%$ & & \\
\hline 2006 & 20,645 & 125 & 454 & 571 & 1,343 & 1,797 & $8.70 \%$ & & \\
\hline 2007 & 21,161 & 129 & 583 & 565 & 1,908 & 2,491 & $11.77 \%$ & & \\
\hline 2008 & 21,690 & 132 & 715 & 560 & 2,468 & 3,183 & $14.67 \%$ & & \\
\hline 2009 & 22,233 & 135 & 850 & 555 & 3,023 & 3,873 & $17.42 \%$ & & \\
\hline 2010 & 22,788 & 138 & 988 & 550 & 3,573 & 4,561 & $20.01 \%$ & 6.56 & 0.613 \\
\hline 2011 & 23,358 & 142 & 1,130 & 546 & 4,119 & 5,249 & $22.47 \%$ & & \\
\hline 2012 & 23,942 & 145 & 1,275 & 543 & 4,662 & 5,937 & $24.80 \%$ & & \\
\hline 2013 & 24,541 & 149 & 1,424 & 540 & 5,202 & 6,626 & $27.00 \%$ & & \\
\hline 2014 & 25,154 & 153 & 1,577 & 537 & 5,739 & 7,316 & $29.08 \%$ & & \\
\hline 2015 & 25,783 & 157 & 1,734 & 535 & 6,274 & 8,008 & $31.06 \%$ & & \\
\hline 2016 & 26,428 & 161 & 1,895 & 533 & 6,807 & 8,702 & $32.93 \%$ & & \\
\hline 2017 & 27,088 & 165 & 2,060 & 531 & 7,338 & 9,398 & $34.69 \%$ & & \\
\hline 2018 & 27,766 & 169 & 2,229 & 530 & 7,868 & 10,097 & $36.37 \%$ & & \\
\hline 2019 & 28,460 & 173 & 2,402 & 530 & 8,398 & 10,800 & $37.95 \%$ & & \\
\hline 2020 & 29,171 & 177 & 2,579 & 529 & 8,927 & 11,506 & $39.44 \%$ & 16.59 & 1.550 \\
\hline
\end{tabular}


Market Penetration, Energy Savings, and $\mathrm{CO}_{2}$ Decrease for Multiport Dryer Technology

\begin{tabular}{|c|c|c|c|}
\hline \multicolumn{2}{|c|}{ Paper and Paperboard } & & \\
\hline \multicolumn{2}{|c|}{ Assumptions for Energy Consumption } & \multicolumn{2}{|c|}{ Assumptions for $\mathrm{CO}_{2}$ emission decrease } \\
\hline $3.90 \mathrm{E}+06$ & Btu/ton of paper & 113 & pounds $\mathrm{CO}_{2}$ per million Btu for Natural Gas \\
\hline 5000 & ton/yr/dryer & $19 \%$ & Fraction of Energy Consumption as Natural Gas \\
\hline $3.45 \%$ & savings per retrofit dryer & & \\
\hline 2 & Factor for ancillary savings & 161 & pounds $\mathrm{CO}_{2}$ per million Btu for Oil \\
\hline 3.00 & penetration rate, $\%$ per year & $30 \%$ & Fraction of Energy Consumption as Oil \\
\hline $3.90 \mathrm{E}+06$ & Btu/ton of paper & 208 & pounds $\mathrm{CO}_{2}$ per million Btu for Coal \\
\hline 5000 & ton/yr/dryer & $1 \%$ & Fraction of Energy Consumption as Coal \\
\hline $4.55 \%$ & savings per new dryer & & \multirow{2}{*}{ pounds $\mathrm{CO}_{2}$ per million Btu for Black Liquor } \\
\hline 2 & Factor for ancillary savings & 230 & \\
\hline 25.00 & penetration rate, $\%$ per year & $50 \%$ & Fraction of Energy Consumption as Black Liquor \\
\hline & & & pounds $\mathrm{CO}_{2}$ per million Btu for Other \\
\hline & & & Fraction of Energy Consumption as Other \\
\hline & & & \\
\hline
\end{tabular}


Market Penetration, Energy Savings, and $\mathrm{CO}_{2}$ Decrease for Multiport Dryer Technology

\begin{tabular}{|c|c|c|c|c|c|c|c|c|c|}
\hline & 8 & \multicolumn{4}{|c|}{ million tons market pulp per year } & & & & \\
\hline & $80 \%$ & are cylin & r dryers & & 2.50 & \multicolumn{2}{|c|}{$\%$ growth per year } & & \\
\hline & $\begin{array}{l}\text { Number } \\
\text { of dryers } \\
\text { in }\end{array}$ & \multicolumn{5}{|c|}{ Calculations for Market Pulp } & $\begin{array}{c}\text { Market } \\
\text { penetra- } \\
\text { tion }\end{array}$ & $\begin{array}{l}\text { Energy } \\
\text { Savings }\end{array}$ & $\begin{array}{l}\text { Decreased } \\
\mathrm{CO}_{2} \\
\text { Emissions }\end{array}$ \\
\hline & service & & & & & & $\begin{array}{c}\% \text { of } \\
\text { dryers }\end{array}$ & $\begin{array}{c}10^{12} \\
\text { Btu/yr }\end{array}$ & $\begin{array}{c}10^{6} \\
\text { tons/yr }\end{array}$ \\
\hline & & 25.00 & & 3.00 & & & & & \\
\hline & & new & total new & retrofit & total retro & total & & $\begin{array}{r}\text { Savings f } \\
\text { Dr }\end{array}$ & $\begin{array}{l}\text { r Retrofit } \\
\text { ers }\end{array}$ \\
\hline 1996 & 1,280 & 0 & & 0 & & & $0.00 \%$ & 0.0013455 & 134.35 \\
\hline 1997 & 1,312 & 0 & & 0 & & & $0.00 \%$ & $\begin{array}{c}10^{12} \\
\mathrm{Btu} / \mathrm{yr}\end{array}$ & tons/yr \\
\hline 1998 & 1,345 & 0 & & 0 & & & $0.00 \%$ & per dryer & per dryer \\
\hline 1999 & 1,738 & 0 & & 0 & & & $0.00 \%$ & & \\
\hline 2000 & 1,413 & 1 & 1 & 2 & 2 & 3 & $0.21 \%$ & & \\
\hline 2001 & 1,448 & 2 & 3 & 6 & 8 & 11 & $0.76 \%$ & $\begin{array}{l}\text { Savings } \\
\text { Dryers }\end{array}$ & for New \\
\hline 2002 & 1,484 & 4 & 7 & 13 & 21 & 28 & $1.89 \%$ & 0.0017745 & 177.18 \\
\hline 2003 & 1,522 & 8 & 15 & 19 & 40 & 55 & $3.61 \%$ & $\begin{array}{c}10^{12} \\
\mathrm{Btu} / \mathrm{yr}\end{array}$ & tons/yr \\
\hline 2004 & 1,560 & 9 & 24 & 27 & 67 & 91 & $5.83 \%$ & per dryer & per dryer \\
\hline 2005 & 1,599 & 9 & 33 & 35 & 102 & 135 & $8.45 \%$ & & \\
\hline 2006 & 1,639 & 9 & 42 & 43 & 145 & 187 & $11.41 \%$ & & \\
\hline 2007 & 1,679 & 10 & 52 & 43 & 188 & 240 & $14.29 \%$ & & \\
\hline 2008 & 1,721 & 10 & 62 & 43 & 231 & 293 & $17.02 \%$ & & \\
\hline 2009 & 1,764 & 10 & 72 & 42 & 273 & 345 & $19.55 \%$ & & \\
\hline 2010 & 1,809 & 11 & 83 & 42 & 315 & 398 & $22.01 \%$ & 0.57 & 0.057 \\
\hline 2011 & 1,854 & 11 & 94 & 42 & 357 & 451 & $24.33 \%$ & & \\
\hline 2012 & 1,900 & 11 & 105 & 42 & 399 & 504 & $26.52 \%$ & & \\
\hline 2013 & 1,948 & 11 & 116 & 41 & 440 & 556 & $28.55 \%$ & & \\
\hline 2014 & 1,996 & 12 & 128 & 41 & 481 & 609 & $30.51 \%$ & & \\
\hline 2015 & 2,046 & 12 & 140 & 41 & 522 & 662 & $32.35 \%$ & & \\
\hline 2016 & 2,097 & 12 & 152 & 41 & 563 & 715 & $34.09 \%$ & & \\
\hline 2017 & 2,150 & 13 & 165 & 41 & 604 & 769 & $35.77 \%$ & & \\
\hline 2018 & 2,204 & 13 & 178 & 41 & 645 & 823 & $37.35 \%$ & & \\
\hline 2019 & 2,259 & 13 & 191 & 41 & 686 & 877 & $38.83 \%$ & & \\
\hline 2020 & 2,315 & 14 & 205 & 41 & 727 & 932 & $40.26 \%$ & 1.34 & 0.134 \\
\hline
\end{tabular}


Market Penetration, Energy Savings, and $\mathrm{CO}_{2}$ Decrease for Multiport Dryer Technology

\begin{tabular}{|c|c|c|c|}
\hline \multicolumn{2}{|l|}{ Market Pulp } & & \\
\hline \multicolumn{2}{|c|}{ Assumptions for Energy Consumption } & \multicolumn{2}{|c|}{ Assumptions for $\mathrm{CO}_{2}$ emission decrease } \\
\hline & & & \\
\hline $3.90 \mathrm{E}+06$ & Btu/ton of paper & 113 & pounds $\mathrm{CO}_{2}$ per million Btu for Natural Gas \\
\hline 5000 & ton/yr/dryer & $20 \%$ & Fraction of Energy Consumption as Natural Gas \\
\hline $3.45 \%$ & savings per retrofit dryer & & Deunds COn ner million Rtu for Oil \\
\hline 2 & Factor for ancillary savings & 161 & pounds $\mathrm{CO}_{2}$ per million Btu for Oil \\
\hline 3.00 & penetration rate, $\%$ per year & $10 \%$ & Fraction of Energy Consumption as Oil \\
\hline $3.90 \mathrm{E}+06$ & Btu/ton of paper & 208 & pounds $\mathrm{CO}_{2}$ per million Btu for Coal \\
\hline 5000 & ton/yr/dryer & $0 \%$ & Fraction of Energy Consumption as Coal \\
\hline $4.55 \%$ & savings per new dryer & & \multirow{2}{*}{ pounds $\mathrm{CO}_{2}$ per million Btu for Black Liquor } \\
\hline 2 & Factor for ancillary savings & 230 & \\
\hline 25.00 & penetration rate, $\%$ per year & $70 \%$ & Fraction of Energy Consumption as Black Liquor \\
\hline & & & pounds $\mathrm{CO}_{2}$ per million $\mathrm{Btu}$ for Other \\
\hline & & & Fraction of Energy Consumption as Other \\
\hline & & & \\
\hline
\end{tabular}

Table A1. Energy savings and decreased $\mathrm{CO}_{2}$ emissions by Multiport Dryer technology

\begin{tabular}{||c|c|c|c||}
\hline \hline & $\begin{array}{c}\text { Paper and Paperboard } \\
\text { Production }\end{array}$ & $\begin{array}{c}\text { Market Pulp } \\
\text { Production }\end{array}$ & Total \\
\hline Year 2010 Projection & 6.56 & 0.57 & 7.13 \\
\hline $\begin{array}{r}\text { Energy Savings, } \\
\text { trillion Btu/year }\end{array}$ & 0.613 & 0.057 & 0.67 \\
\hline $\begin{array}{c}\text { Decreased CO2 Emissions, } \\
\text { million tons/year }\end{array}$ & 16.59 & 1.34 & 17.93 \\
\hline $\begin{array}{c}\text { Year 2020 Projection } \\
\text { trillion Btu/year }\end{array}$ & 1.55 & 0.13 & 1.68 \\
\hline $\begin{array}{c}\text { Energy Savings, } \\
\text { million tons/year }\end{array}$ & & & \\
\hline \begin{tabular}{c} 
Decreased CO2 Emissions, \\
\hline
\end{tabular}
\end{tabular}


Distribution for ANL-01/28

$\underline{\text { Internal }}$

Y. S. Cha

J. R. Hull (10)

A. M. Tentner

T. H. Chien

K. E. Kasza

R. A. Valentin

S. U. S. Choi (50)

T. M. Mulcahy

M. W. Wambsganss

R. Doctor

N. T. Obot

W. Yu

H. Drucker

R. B. Poeppel

TIS Files

J. Harkness

W. W. Schertz

J. Harmon

J. A. Stephens

$\underline{\text { External }}$

ANL Libraries

ANL-E

ANL-W

D. K. Barde, Eastern Pulp and Paper Corp., Amherst, MA

D. J. Boron, DOE OIT

E. H. Fleischman, Idaho National Engineering and Environmental Laboratory

D. M. France, University of Illinois at Chicago

D. Friedman, AFPA (20)

D. W. Robertson, DOE Idaho Operations Office

V. A. Robinson, DOE OIT

C. W. Stewart, Eastern Pulp and Paper Corp., Amherst, MA

J. L. Timm, The Johnson Corp., Three Rivers, MI

W. D. Vallance, Eastern Pulp and Paper Corp., Amherst, MA

Energy Technology Division Review Committee

H. K. Birnbaum, University of Illinois at Urbana-Champaign

I.-W. Chen, University of Pennsylvania

F. P. Ford, Rexford, NY

S. L. Rohde, University of Nebraska-Lincoln

H. S. Rosenbaum, Fremont, CA

S. L. Sass, Cornell University

R. Zoughi, University of Missouri-Rolla 